\title{
Transcriptional regulation of metal metabolism- and nutrient absorption-related genes in Eucalyptus grandis by arbuscular mycorrhizal fungi at different zinc concentrations
}

Xinyang Wang, Jingwei Liang, Ziyi Liu, Yuxuan Kuang, Lina Han, Hui Chen, Xianan Xie, Wentao Hu*and Ming Tang ${ }^{*}$

\begin{abstract}
Background: Eucalyptus spp. are candidates for phytoremediation in heavy metal (HM)-polluted soils as they can adapt to harsh environments, grow rapidly, and have good economic value. Arbuscular mycorrhizal fungi (AMF) are the most widely distributed plant symbiotic fungi in nature, and they play an important role in promoting the phytoremediation of HM-polluted soils. However, few studies have evaluated the HM detoxification mechanism of E. spp. in symbiosis with AMF, and thus, the molecular mechanism remains unclear.

Results: The gene transcription and metabolic pathways of $E$. grandis were studied with and without inoculation with AMF and at different zinc (Zn) concentrations. Here, we focused on the transcript level of six HM-related gene families (ZNT, COPT/Ctr, YSL, ZIFL and CE). Under high-Zn conditions, thirteen genes (ZNT:2, COPT/Ctr:5, YSL:3, ZIFL:1, CE:2) were upregulated, whereas ten genes (ZNT:3, COPT/Ctr:2, YSL:3, ZIFL:1, CE:1) were downregulated. With AMF symbiosis under high-Zn conditions, ten genes (ZNT:4, COPT/Ctr:2, YSL:3, CE:1) were upregulated, whereas nineteen genes (ZNT:9, COPT/Ctr:2, YSL:3, ZIFL:4, CE:1) were downregulated. Under high-Zn conditions, genes of three potassium-related transporters, six phosphate transporters (PHTs), and two nitrate transporters (NRTs) were upregulated, whereas genes of four potassium-related transporters,four PHTs, and four nitrogen-related transporters were downregulated. With AMF symbiosis under high-Zn conditions, genes of two potassium-related transporters, six ammonium transporters (AMTs) and five PHTs were upregulated, whereas genes of six potassium-related transporters, two AMTs and five PHTs were downregulated.
\end{abstract}

Conclusions: Our results indicates that AMF increases the resistance of E. grandis to high-Zn stress by improving nutrients uptake and regulating Zn uptake at the gene transcription level. Meanwhile, our findings provide a genome-level resource for the functional assignments of key genes regulated by $Z n$ treatment and AM symbiosis in

\footnotetext{
*Correspondence: hwt@scau.edu.cn; tangmingyl@163.com State Key Laboratory of Conservation and Utilization of Subtropical Agro-bioresources, Guangdong Laboratory for Lingnan Modern Agriculture, Guangdong Key Laboratory for Innovative Development and Utilization of Forest Plant Germplasm, College of Forestry and Landscape Architecture, South China Agricultural University, Guangzhou 510642, China
} permits use, sharing, adaptation, distribution and reproduction in any medium or format, as long as you give appropriate credit to the original author(s) and the source, provide a link to the Creative Commons licence, and indicate if changes were made. The images or other third party material in this article are included in the article's Creative Commons licence, unless indicated otherwise in a credit line to the material. If material is not included in the article's Creative Commons licence and your intended use is not permitted by statutory regulation or exceeds the permitted use, you will need to obtain permission directly from the copyright holder. To view a copy of this licence, visit http://creativecommons.org/licenses/by/4.0/. The Creative Commons Public Domain Dedication waiver (http://creativeco mmons.org/publicdomain/zero/1.0/) applies to the data made available in this article, unless otherwise stated in a credit line to the data. 
six HM-associated gene families and macromineral nutrient-related gene families of E. grandis. This may contribute to the elucidation of the molecular mechanisms of the response to Zn stress in E. grandis with AM symbiosis at the aspect of the interaction between HM tolerance and nutrient acquisition.

Keywords: Eucalyptus grandis, Zinc stress, Arbuscular mycorrhizal fungi, Genes transcript level

\section{Background}

Large quantities of heavy metals (HMs), such as zinc $(\mathrm{Zn})$, copper $(\mathrm{Cu})$, iron $(\mathrm{Fe})$, and cadmium $(\mathrm{Cd})$, are often released into the soil as a result of soil acidity, flooding, mining, industrial activities, or other sources of pollution [1]. HM contamination reduces the area of usable land and restricts the distribution of vegetation. Moreover, in tailings areas, the bioaccumulation of heavy metals in plants and animals causes serious harm to the food chain and, consequently, human health. To eliminate HMs from the ecosystem, bioremediation and phytoremediation are the most significant and appropriate strategies [2]. Phytoextraction and phytostabilization are the main methods used for phytoremediation [3]. Many plants have been developed for phytoextraction and phytostabilization. For example, Brown et al. [4] discovered that Thlaspi caerulescens super-accumulates $\mathrm{Zn}$ and $\mathrm{Cd}$, indicating that the plant has potential remediation capacity in HMcontaminated soil. Blaylock et al. [5] found that mustard greens (Brassica juncea) can absorb and accumulate various HMs, such as lead (Pb), Cd, and $\mathrm{Zn}$, and that Thlaspi can effectively absorb Zn, Pd, and Cd. However, many of the plants currently used for the bioremediation of $\mathrm{HM}$ pollution have slow growth and low biomass content $[6$, 7]. Therefore, to improve remediation efficiency, a feasible direction for the bioremediation of HM-contaminated soil is to screen for plants that are fast-growing, have high biomass content, and are HM tolerant.

Eucalyptus grandis has the characteristics of fast growth, strong stress resistance, and high economic value [8]. Both E. grandis 5 and E. grandis $\times E$. uroplrlla can adapt to severe environments in mining areas and also have strong phytoremediation potential [9]. In some mining areas polluted with $\mathrm{Zn}$, Eucalyptus spp. have been shown to be HM pollution hyperaccumulators [10]. In the Huangpu District of Guangzhou, where $\mathrm{Zn}$ pollution is a serious problem, E. urophylla became the dominant species [11]. These data suggest that Eucalyptus spp. are potential tools to remedy $\mathrm{Zn}$ pollution in the soil [12]. Moreover, Eucalyptus spp. can establish symbioses with arbuscular mycorrhizal fungi (AMF) and ectomycorrhizal (ECM) fungi [13]. Campos et al. [14] found AMF/ ECM fungi symbioses at all ages of $E$. grandis and $E$. urophylla.

$\mathrm{Zn}$ can be toxic if it accumulates in excess amounts, although it is also an essential nutrient for plant growth at low concentrations [15]. Zn toxicity often occurs in soils contaminated by mining and smelting activities, in agricultural soils treated with sewage sludge, and in urban soils enriched with anthropogenic $\mathrm{Zn}$ inputs [16]. To respond to $\mathrm{Zn}$ toxicity, plants require a tightly controlled metal homeostasis network that balances the uptake, utilization, and tolerance of $\mathrm{Zn}[17,18]$. Znrelated transporters are involved in the absorption, intracellular transport, localization, and efflux of $\mathrm{Zn}$. These include the P1B-type heavy metal ATPase (HMA), Znand Fe-regulated transporter-like protein (ZIP), copper transporter (COPT/Ctr), yellow stripe-like (YSL) transporter, Zn-induced facilitator1 (ZIF1) transporter, and cation efflux (CE) transporter families.

There is convincing evidence that mycorrhizal associations are of major importance in reducing metal transfer to plants [19] or serving as an effective exclusion barrier against the transport of these elements from roots to shoots [20]. In addition, mycorrhizal fungi, especially AMF, favor the absorption of nitrogen $(\mathrm{N})$, phosphorus $(\mathrm{P})$, and potassium (K) [21]. AMF also improve the tolerance of plants to HM stress [22], prevent plant contact with HMs, and favor the extraction of HMs from the soil [23]. As many plants form AMF symbioses, even in highly HM-contaminated soils [24], AMF may be an important tool for the remediation of HM-contaminated soils [25]. Inoculation with AMF can improve the nutritional status of Eucalyptus spp. by increasing N, P, and $\mathrm{K}$ concentrations and improve the tolerance of Eucalyptus spp. to HM stress [26]. Previous studies have shown that under conditions of $\mathrm{Pb}$ stress, AMF symbiosis can increase the uptake of $\mathrm{Pb}$ by the shoots of E. globulus [27]. However, few studies have focused on the mechanism of $\mathrm{Zn}$ tolerance and enrichment in Eucalyptus spp. with AMF symbiosis. It is necessary to explore the detoxification mechanism of Eucalyptus spp. in response to $\mathrm{Zn}$ stress, as this may provide the theoretical basis for the ecological restoration of artificial $E$. grandis forests in Zn-contaminated areas.

In this study, to better understand the mechanisms of the response to $\mathrm{Zn}$ stress in E. grandis with AMF symbiosis, candidate genes were screened using RNA sequencing (RNA-seq) analysis of E. grandis under different zinc chloride $\left(\mathrm{ZnCl}_{2}\right)$ concentrations. Important response pathways, genes involved in $\mathrm{Zn}$ tolerance, and gene families associated with nutrient absorption were 
identified. This aim of this study was to determine (i) the type of metal transporters that are regulated by different $\mathrm{Zn}$ concentrations and (ii) the type of HM transporters and nutrient-associated transporters that respond to $\mathrm{Zn}$ treatment with AMF symbiosis. These results may contribute to a greater understanding of Zn-responsive mechanisms in E. grandis with AMF symbiosis.

\section{Results and discussion}

In this study, we investigated genes involved in $\mathrm{Zn}$ and nutrient absorption by the transcriptome analysis of $E$. grandis with AMF symbiosis under different $\mathrm{Zn}$ concentrations, followed by the putative subcellular localization and functional prediction of DEGs. Correlations among genes belonging to the same gene family were also analyzed. After inoculation with AMF under high-Zn conditions, 2253 DEGs were identified, of which 1683 were upregulated and 570 were downregulated. However, only 539 DEGs were identified under high-Zn conditions without AMF inoculation, of which 275 were upregulated and 264 were downregulated (Supplementary Fig. S1). These findings represent the first step in determining the molecular mechanisms of the response of $E$. grandis to high-Zn stress and provide plenty of new candidate genes for studies on tolerant germplasm development and molecular biology in woody plants.

\section{Translocation and accumulation of $\mathrm{Zn}$ in mycorrhizal Eucalyptus}

There were no obvious symptoms of visual toxicity, regardless of metal addition or AMF inoculation. Because the metal treatment was performed after the inoculation, the colonization rate did not change significantly, but the arbuscule abundance decreased significantly and the number of hyphae increased under high- $\mathrm{Zn}$ conditions (Supplementary Fig. S2).

Compared with the normal $\mathrm{Zn}$ concentration, the high Zn concentration caused a 35\% reduction in the Pi content of the shoots of E. grandis, but the Pi content of the roots did not change significantly (Supplementary Fig. S3). After inoculation with AMF, the Pi content of the shoots increased, indicating that AMF increased the Pi content of E. grandis (Supplementary Fig. S3). The preexperiment shows that $E$. grandis can promote plant growth after inoculation with AMF (Supplementary Fig. S4). These results also indicate that there is an antagonistic relationship between $\mathrm{Zn}$ and $\mathrm{P}$ in Eucalyptus spp. and that mycorrhizal plants may reduce HM-induced damage to plants through $\mathrm{P}$ absorption. The interconnection between these two nutrients has been observed in many crop species and can be summarized as follows: Zn-deficient plants over-accumulate Pi in the shoots and, conversely, Pi-deficient plants overaccumulate $\mathrm{Zn}$ in the shoots [28]. Mycorrhizae play an important role in the acquisition of $\mathrm{P}$ by the host plant [29], and they may also facilitate $\mathrm{Zn}$ transport in the soil-fungi-plant continuum [19]. Nevertheless, the molecular basis of the Pi-Zn interaction in plants remains poorly understood in both mycorrhizal and non-mycorrhizal plants [30].

\section{Transporters that introduce metals into the cytosol}

As seedlings from the NM- and AMF-treatment groups demonstrated distinct patterns of $\mathrm{Zn}$ and $\mathrm{P}$ contents in their acclimation to $\mathrm{Zn}$ availability (Supplementary Fig. S3), specific differences may also be expected in the transcriptional regulation pattern of key genes implicated in $\mathrm{Zn}$ metabolism [31]. Therefore, the transcript levels of representative genes involved in $\mathrm{Zn}$ acquisition and assimilation were assessed in the roots of plants in the NM- and AMF-treatment groups.

\section{ZNT family}

ZNTs are micronutrient transporters from the zincresistance transporter and iron-resistance transporterlike protein (ZIP) family. ZIP transporters contain a conserved cytosolic histidine-rich loop between transmembrane (TM) domains 3 and 4 in eukaryotes [32], which is associated with metal specificity and metal transport rate [33].

Nineteen candidate ZNT family genes were identified in the E. grandis genome. The characteristics of these genes, including the open reading frame length, chromosome location, number of exons, and the molecular weight and isoelectric point of the encoded protein were analyzed and are shown in Supplementary Table 1. To identify the evolutionary relationships between EgZNT genes of different plant species, a phylogenetic tree was constructed with 86 ZIP transport protein sequences from 10 plant species (Supplementary Fig. S5). Bioinformatics analyses showed that ZNT genes were well conserved and had similar physicochemical properties. Conserved motif structures were also detected (Supplementary Fig. S6). And the chromosomal location of ZNT gene family were shown in the chromosome-scale genome of E.grandis (Supplementary Fig. S7).

Cluster analysis of transcript levels of the ZNT gene family clearly separated root samples from NM- and AMF-treatment groups based on their responsiveness to Zn (Fig. 1). Nine ZNT genes (ZNT-Eucgr.A00916, ZNT-Eucgr.E01913, ZNT-Eucgr.A00921, ZNT-Eucgr. K01345, ZNT-Eucgr.K01348, ZNT-Eucgr.E01901, ZNTEucgr.K01343, ZNT-Eucgr.F02059, and ZNT-Eucgr. F02060) formed subcluster I. Under high-Zn conditions, the abundance of the transcripts of subcluster I genes in roots from the AMF-treatment group was higher than or similar to that in roots from the NM-treatment group. 


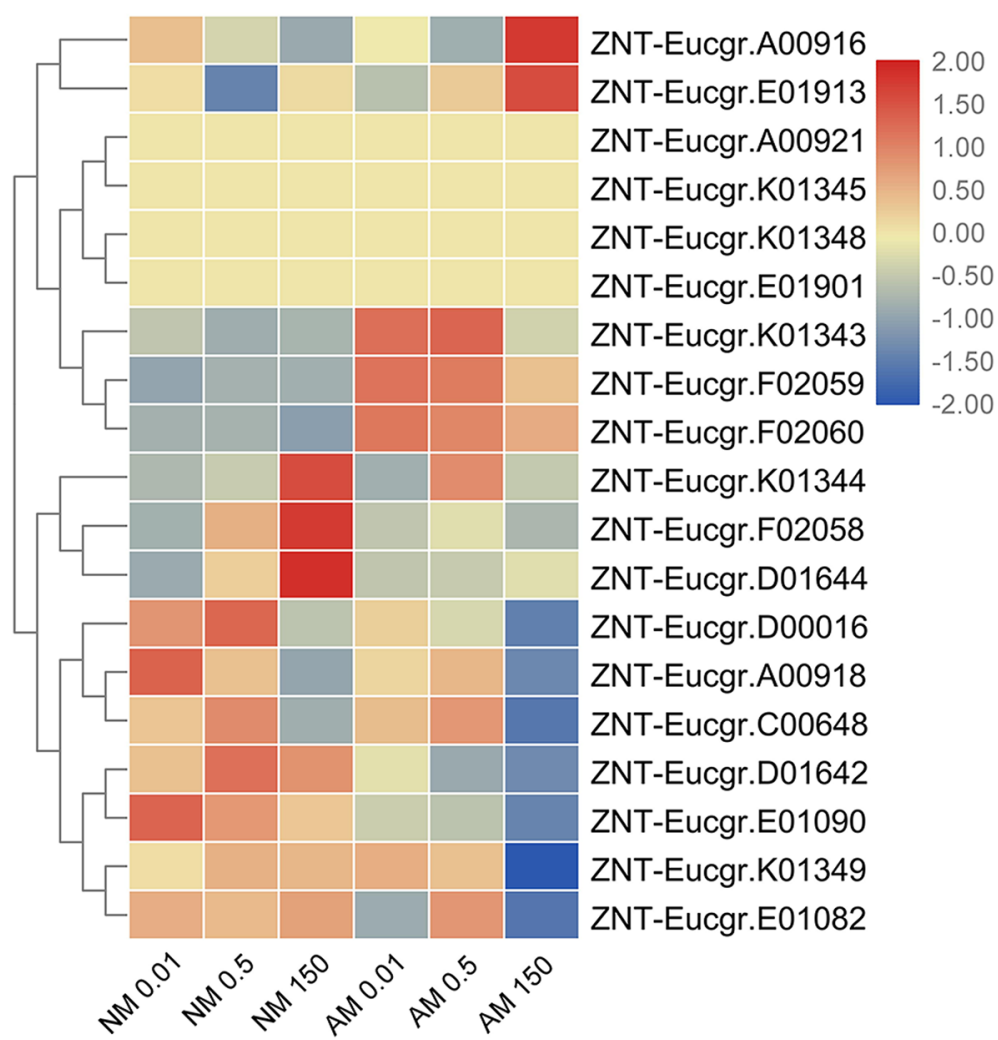

Fig. 1 Heatmap of ZNT family members. Cluster analysis of transcriptional fold-changes of ZNT family gens in roots of non-mycorrhizal and mycorrhizal E. grandis exposed to $0.01,0.5$, or $150 \mu \mathrm{M} \mathrm{ZnCl}_{2}$. The color scale indicates fold-changes of mRNAs. For each gene, the expression levels in non-mycorrhizal roots exposed to $0.5 \mu \mathrm{M} \mathrm{ZnCl}_{2}$ were defined as 1, and the corresponding fold-changes under 0.01 and $150 \mu \mathrm{M} \mathrm{ZnCl}_{2}$ were calculated

The second subcluster of genes included ZNT-Eucgr. K01344, ZNT-Eucgr.F02058, ZNT-Eucgr.D01644, ZNTEucgr.A00918, ZNT-Eucgr.C00648, ZNT-Eucgr.D01642, ZNT-Eucgr.E01090, ZNT-Eucgr.K01349, and ZNT-Eucgr. E01082. The transcript levels of these genes were lower in roots from the AMF-treatment group than in roots from the NM-treatment group under low-Zn conditions.

Limiting the $\mathrm{Zn}$ supply affected the transcript levels of genes involved in $\mathrm{Zn}$ metabolism in the roots from both the AMF- and NM-treatment groups. Generally, the transcript levels of genes from subcluster I were higher in roots from the AMF-treatment group than in those from the NM-treatment group under low-Zn conditions (Fig. 1). However, the transcriptional pattern of ZNTEucgr.E01913 was completely different between the NMand AMF-treatment groups. The transcript levels of this gene were upregulated in roots from the NM-treatment group under low- and high-Zn conditions, whereas in roots from the AMF-treatment group, they were only upregulated under high-Zn conditions. We found that ZNT-Eucgr.E01913, OsIRT1, HvIRT1, AtIRT1, MtZIP1, and MtZIP6 were in the same branch of the phylogenetic tree (Supplementary Fig. S5). HvIRT1 is involved in $\mathrm{Zn}$ absorption under conditions of $\mathrm{Zn}$ deficiency [34]. IRT1 is considered to be the main transporter for $\mathrm{Fe}^{2+}$ uptake in roots and is polarly localized to the soil-facing side of the epidermal plasma membrane [35]. AtIRT1 is involved in Fe uptake. Barberon et al. [35] showed that plants growing under high $\mathrm{Zn}$ concentrations are deficient in iron. Recently, a ZIP transporter gene (MtZIP6) in the model legume Medicago truncatula was identified as being significantly upregulated by AMF colonization when $\mathrm{Zn}$ was at a limiting concentration [36]. The ZIP transporter encoded by MtZIP6 is located in the plasma membrane and is involved in $\mathrm{Zn}$ transport in rhizobial symbioses [37]. However, MtZIP6 has been shown to transport Fe in addition to $\mathrm{Zn}$ [38]. In contrast, the lower affinity of $M t Z I P 1$ for $Z n$ suggests that this transporter plays a role in $\mathrm{Zn}$ transport within the plant, because the concentration of $\mathrm{Zn}$ has been shown to be much higher in plant compartments than in the soil [39]. Therefore, the increase in the expression levels of $Z N T$ Eucgr.E01913 under low-Zn conditions suggested that it is also involved in iron absorption under conditions 
of $\mathrm{Zn}$ deficiency. The increase in the expression levels of ZNT-Eucgr.E01913 under high-Zn conditions may be caused by iron deficiency. This result also suggests that AMF may assist plants to absorb $Z n$ through other mechanisms at low Zn concentrations. Thus, ZNT-Eucgr. E01913 may be involved in regulating the zinc-iron balance in plant roots.

The expression of ZNT-Eucgr.K01343, which is homologous to AtZIP1 (Supplementary Fig. S5), from the ZIP family, was induced under conditions of $\mathrm{Zn}$ deficiency and was inhibited under high-Zn conditions (Fig. 1). AtZIP1 serves as a vacuolar transporter that remobilizes $\mathrm{Zn}$ from the vacuole to the cytoplasm in root cells [40]. AtZIP1 expression is mainly induced under conditions of $\mathrm{Zn}$ deficiency and is involved in $\mathrm{Zn}$ uptake and redistribution [41]. Thus, ZNT-Eucgr.K01 343may also be involved in $\mathrm{Zn}$ uptake and redistribution under conditions of $\mathrm{Zn}$ deficiency.

ZNT-Eucgr.F02059 and ZNT-Eucgr.F02060 have a high degree of homology and are in the unified branch of the phylogenetic tree with OsZIP2, MtZIP7, and AtZIP2(Supplementary Fig. S5). Milner et al. [40] reported that $\mathrm{Zn}$ uptake from the root apoplast is carried out by AtZIP2 in the root endodermis of Arabidopsis thaliana. AtZIP2 is a $\mathrm{Zn}$ uptake transporter that is located mainly in the root stele. The expression levels of ZNT-Eucgr.F02059 and ZNT-Eucgr.F02060 were low under NM conditions and were not affected by the $\mathrm{Zn}$ concentration. The levels of these two transcripts increased significantly after AMF inoculation, but their levels decreased with the increase in $\mathrm{Zn}$ concentration with AM treatment. MtZIP7, a putative $\mathrm{Zn}$ and manganese $(\mathrm{Mn})$ transporter, is expressed in both arbusculecolonized and adjacent non-colonized cortical cells [42]. Our results showed that the expression of ZNT-Eucgr. F02059 and ZNT-Eucgr.F02060 is specifically induced by mycorrhizae. AMF contribute to $\mathrm{Zn}$ uptake by their host plants and alleviate HM toxicity. Therefore, ZNTEucgr.F02059 and ZNT-Eucgr.F02060 were specifically induced by AMF symbiosis, and their encoded proteins may transport $\mathrm{Zn}$ released by the AMF at the symbiotic interface.

Of the ZNTs in subcluster II, the transcript abundance of ZNT-Eucgr.D01642, ZNT-Eucgr.D01644, ZNT-Eucgr. E01082, and ZNT-Eucgr.E01090 decreased after inoculation with AMF under high-Zn conditions (Fig. 1). These genes are in the same branch of the phylogenetic tree and are highly homologous, but only ZNT-Eucgr. D01644 was induced by a high $\mathrm{Zn}$ concentration without AMF. These four transporters are in the same subfamily as MtZIP2 and AsZIP2 in the phylogenetic tree (Supplementary Fig. S5) The expression level of AsZIP2 has been shown to increase with increasing $\mathrm{Zn}$ concentration
[43]. ZNT-Eucgr.D01644 may have the same function as MtZIP2 to transport excess $\mathrm{Zn}$ from the intercellular space into the vacuole and thus maintain a suitable cytoplasmic Zn concentration [44]. As shown in Fig. 1, AMF symbiosis effectively inhibited the transcript levels of this subfamily, presumably because AMF symbiosis inhibits excessive $\mathrm{Zn}$ absorption [44]. There are two possible explanations for this phenomenon. First, AM fungal hyphae bind and fix HMs on the fungal cell wall, thus reducing the absorption of heavy metals by the host plant. Second, AMF deposit and chelate HMs in the rhizosphere [45].

We performed Pearson's correlation analysis of the ZNT family genes and found that the transcript levels of ZNT-Eucgr.K01343 and ZNT-Eucgr.F02060 $(R=0.739)$, ZNT-Eucgr.F02059 and ZNT-Eucgr.F02060 $(R=0.953)$, ZNT-Eucgr.D01644 and ZNT-Eucgr.F02058 $(R=0.765)$, and ZNT-Eucgr.K01344 and ZNT-Eucgr.E01901 $(R=0.78)$ were highly significantly correlated $(P<0.001$, Supplementary Table. S2).

\section{COPT/Ctr transporters}

$\mathrm{Cu}$ transporters are known as COPTs in plants [46] and Ctrs in animals and fungi [47]. In plants, COPTs have been suggested to play a role in $\mathrm{Cu}$ uptake from the soil and $\mathrm{Cu}$ delivery to pollen [48]. The PtCOPT gene of Populus trichocarpa is expressed in many tissues and may be involved in regulating plant development [49]. Previous studies have indicated that the COPT/Ctr gene family in animals and herbaceous plants is induced during deficiencies and excesses of $\mathrm{Cu}[50]$ and by $\mathrm{Fe}, \mathrm{Mn}$, and $\mathrm{Zn}$ stress [51].

Twenty-one candidate COPT/Ctr family genes were identified in the $E$. grandis genome. Heat maps showed that COPTs were divided into two subclusters (Fig. 2). In roots, COPT-Eucgr.E04213, COPT-Eucgr.A00965, COPTEucgr.B03028, COPT-Eucgr.00718, COPT-Eucgr.E00673, COPT-Eucgr.L01980, Ctr-Eucgr.B02736, COPT-Eucgr. A02786, COPT-Eucgr.D01867, COPT-Eucgr.H01538, COPT-Eucgr.LO3723, COPT-Eucgr.A00960, and COPTEucgr.A00963 formed subcluster I (Fig. 2). Subcluster I was divided into two small clusters. The transcript abundance of COPT-Eucgr.E04213, COPT-Eucgr.A00965, COPT-Eucgr.B03028, COPT-Eucgr.00718, COPT-Eucgr. E00673, and COPT-Eucgr.L01980 in subcluster I was higher under low- and high-Zn conditions in both the NM- and AMF-treatment groups compared with their levels under normal-Zn condition. The expression levels of genes in the other cluster were diverse. For example, the expression level of Ctr-Eucgr.B02736 induced by AMF increased significantly under both low- and high$\mathrm{Zn}$ conditions, and its expression level under high- $\mathrm{Zn}$ conditions decreased after NM and AMF treatments. 


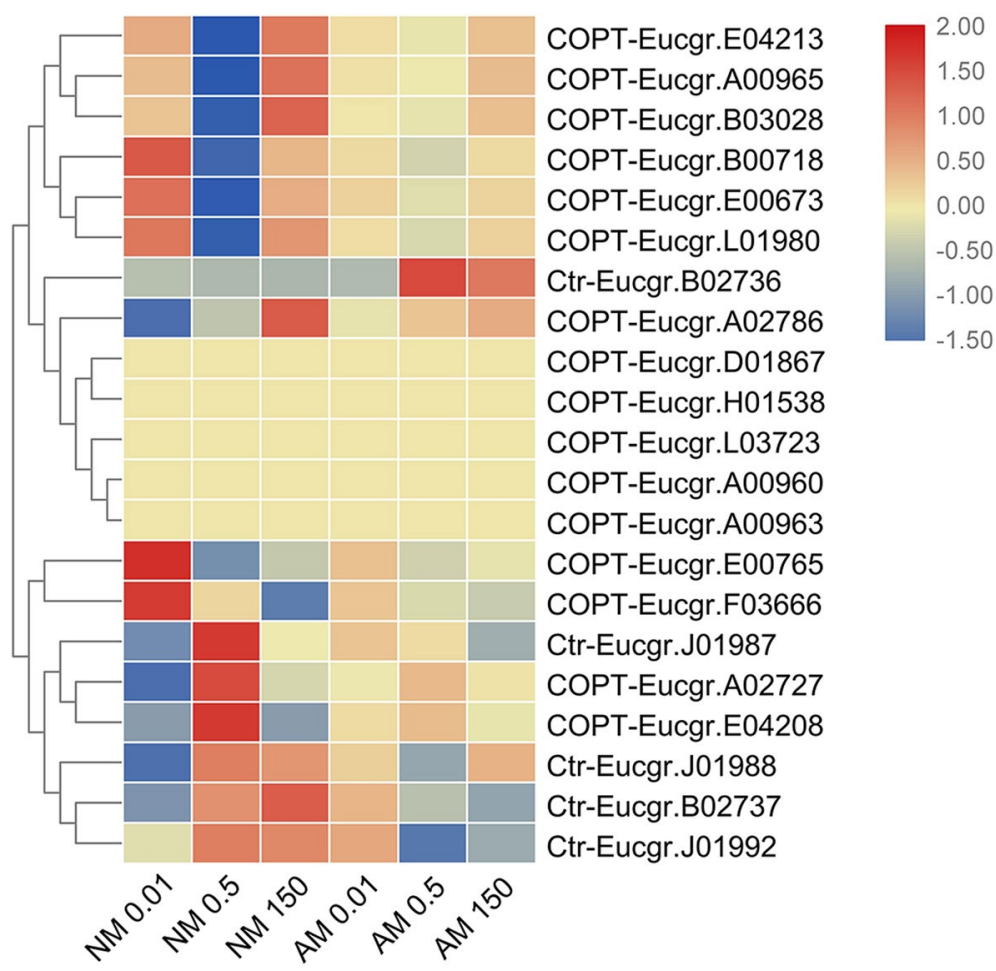

Fig. 2 Heatmap of COPT/Ctr family members. Cluster analysis of transcriptional fold-changes of COPT/Ctr family gens in roots of non-mycorrhizal and mycorrhizal E. grandis exposed to $0.01,0.5$, or $150 \mu \mathrm{M} \mathrm{ZnCl} 2$. The color scale indicates fold-changes of mRNAs. For each gene, the expression levels in non-mycorrhizal roots exposed to $0.5 \mathrm{\mu M} \mathrm{ZnCl}_{2}$ were defined as 1, and the corresponding fold-changes under 0.01 and $150 \mu \mathrm{M} \mathrm{ZnCl} \mathrm{Z}_{2}$ were calculated

The second subcluster consisted of COPT-Eucgr. E00765, COPT-Eucgr.03666, Ctr-Eucgr.J01987, COPTEucgr.A02727, COPT-Eucgr.E04208, Ctr-Eucgr.J01988, COPT-Eucgr.B02737, and Ctr-Eucgr.J01992. The transcript levels of these genes, except COPT-Eucgr.E00765 and COPT-Eucgr.03666, were similar or lower after NM and AMF treatments under low-Zn conditions compared with their levels under normal-Zn conditions (Fig. 2).

Most members of the COPT gene family of $E$. grandis were in the same branch of the phylogenetic tree, indicating that the genes of this family are highly conserved in $E$. grandis (Supplementary Fig. S8).

Based on a comparison of transcriptome and JGI data, two groups of Ctrs and COPTs were identified in E. grandis. Sixteen of these genes were classified as COPTs and five were classified as Ctrs (Fig. 2). The five Ctr transporters had a high degree of homology with the previously reported PtCOPT gene of P. trichocarpa. In all COPT/Ctr transporters, motif 1 and motif 3 corresponded to the TM sites. It is noteworthy that motif 1 contained both the MxxxM and GxxxG motifs (Supplementary Fig. S9). The MxxxM motif is essential for $\mathrm{Cu}$ acquisition [52], and the conserved GxxxG motif is essential for trimerization in hCtr1 [53]. Previous studies of COPT/Ctr families in animals and herbaceous plants have demonstrated their upregulation during deficiencies and excesses of $\mathrm{Cu}[50]$ and in response to $\mathrm{Fe}, \mathrm{Mn}$, and $\mathrm{Zn}$ stress [51]. And the chromosomal location of COPT/Ctr gene family were shown in the chromosome-scale genome of E.grandis (Supplementary Fig. S10).

Heatmap analysis revealed that the expression of EgCOPT genes was induced under both limited and excessive Zn concentrations (Fig. 2). This result is consistent with the PtCOPT expression pattern previously identified in $P$. tomentosa [49]. Quantitative reverse transcription-PCR analysis has shown that the expression of $P t C O P T$ genes is induced under conditions of limited and excessive $\mathrm{Zn}$ [49]. After inoculation with AMF, under low- $\mathrm{Zn}$ conditions, EgCOPT promoted the absorption of $\mathrm{Zn}$ and increased the $\mathrm{Zn}$ concentration in the plant, resulting in decreased expression levels of EgCOPTs. Under high-Zn conditions, mycorrhizal fungi can absorb excess $\mathrm{Zn}$, reduce the $\mathrm{Zn}$ concentration in the plant, and reduce the expression level of $E g C O P T$ (Fig. 2). This result indicates that mycorrhizal fungi can maintain the balance between HM ions in the host plant, thereby reducing the impact of HM ions. Under Zn stress, mycorrhizal fungi 
have been shown to downregulate plant $\mathrm{Zn}$ transporters to promote homeostasis [54].

We performed Pearson's correlation analysis of the COPT/Ctr family genes and found that the transcript levels of COPT-Eucgr.A00965 and COPT-Eucgr.E00673 $(R=0.772)$ and COPT-Eucgr.E00765 and COPT-Eucgr. E04213 $(R=0.748)$ were highly significantly correlated $(P<0.001$, Supplementary Table. S3).

\section{YSL transporter family}

YSL family transporters belong to the oligopeptide transporter family and are significant iron transport proteins. YSL transporters do not use free metals as substrates, but complexes of metals with nicotiana amine (NA) or its derivatives [55]. NA is a non-proteogenic amino acid that is synthesized from S-adenosylmethionine by the enzyme NA synthase [56](NAS). Transport by YSL proteins is induced by $\mathrm{H}^{+}$-symport [57]. Additionally, at least some plant oligonucleotide transporters are also associated with metal transport [58], although the identity of the metal complex transported remains elusive. Little is known about the structure of these proteins, with different models proposing a range of 11-16 TM regions [58]. In broad terms, YSL transporters are involved in metal uptake from the soil in monocots and in long-distance metal distribution in both monocots and dicots [59].

Nineteen candidate YSL family genes were identified in the E. grandis genome. Limiting the supply of $\mathrm{Zn}$ affected the transcript levels of genes involved in $\mathrm{Zn}$ metabolism in the roots of both AMF- and NM-treatment groups. In roots, YSL-Eucgr.I01628, YSL-Eucgr. A01430, and YSL-Eucgr.K00010 formed subcluster I (Fig. 3). Under high-Zn conditions, the transcript abundance of genes in subcluster I was higher after NM treatment than after AMF treatment (Fig. 3). The second subcluster consisted of YSL-Eucgr.K02316, YSLEucgr.K02315, YSL-Eucgr.K02319, YSL-Eucgr.K00012, YSL-Eucgr.D01684, YSL-Eucgr.H00652, YSL-Eucgr. H00651, YSL-Eucgr.K00413, YSL-Eucgr.B00833, YSLEucgr.K02320, YSL-Eucgr.K02321, YSL-Eucgr.B00295, YSL-Eucgr.B00296, YSL-Eucgr.B00835, YSL-Eucgr. G02568, and YSL-Eucgr.K02318. Under high-Zn conditions, the transcript levels of these genes were similar

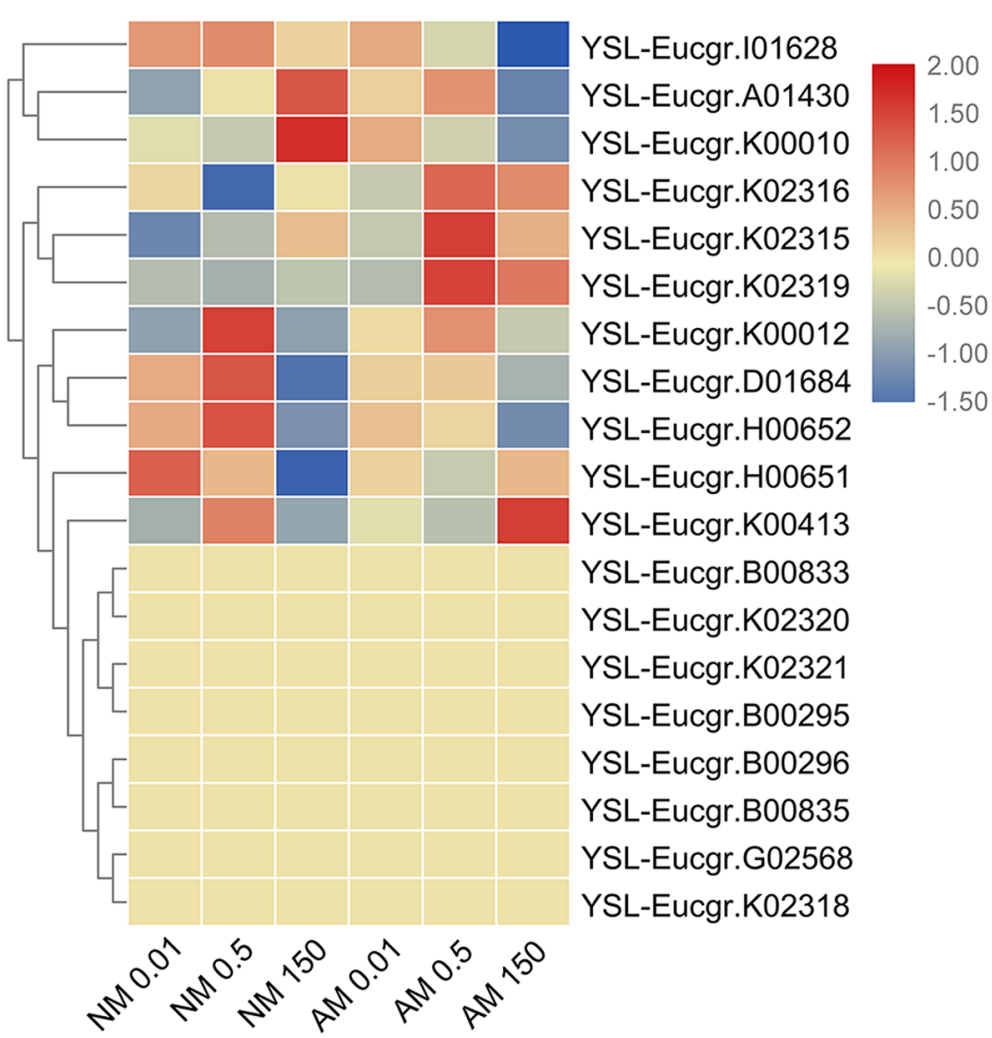

Fig. 3 Heatmap of YSL family members. Heatmap of YSL family members. Cluster analysis of transcriptional fold-changes of COPT/Ctr family gens in roots of non-mycorrhizal and mycorrhizal E. grandis exposed to $0.01,0.5$, or $150 \mu \mathrm{M} \mathrm{ZnCl}$. The color scale indicates fold-changes of mRNAs. For each gene, the expression levels in non-mycorrhizal roots exposed to $0.5 \mu \mathrm{M} \mathrm{ZnCl}_{2}$ were defined as 1 , and the corresponding fold-changes under 0.01 and $150 \mu \mathrm{M} \mathrm{ZnCl}_{2}$ were calculated 
or lower after NM treatment compared with their levels after AMF treatment.

To identify the evolutionary relationships between EgYSL genes of different plant species, a phylogenetic tree was constructed with 50 YSL transport protein sequences from 5 plant species (Supplementary Fig. S11). Bioinformatics analyses showed that YSL genes were well conserved and had similar physicochemical properties. Conserved motif structures were also detected (Supplementary Fig. S12). And the chromosomal location of YSL gene family were shown in the chromosome-scale genome of E.grandis (Supplementary Fig. S13).

We found that the expression level of YSL-Eucgr.K00010 was significantly increased under high- $\mathrm{Zn}$ conditions without AMF inoculation but significantly decreased under high-Zn conditions after with AMF inoculation (Fig. 3). Comparatively, YSL-Eucgr.K00010 expression levels increased after inoculation with AMF under low-Zn conditions. This result showed that after inoculation with AMF, the expression of this gene can be promoted when $\mathrm{Zn}$ concentrations are low and inhibited when $\mathrm{Zn}$ concentrations are high. Therefore, this gene may play a role in both nutrient absorption and metal resistance.

The expression level of YSL-Eucgr.K02319 increased significantly after inoculation with AMF under normal- and high-Zn conditions, and its expression levels decreased after both NM and AMF treatments under high-Zn conditions. We found that YSL-Eucgr.K02319 was in the same branch of the phylogenetic tree as TcYSL5 and TcYSL7 (Supplementary Fig. S11). In situ hybridization showed that TcYSL7 and TcYSL5 are expressed around the vasculature of the shoots and in the central cylinder in the root [60]. Exposure to HMs (Zn, $\mathrm{Cd}$, and nickel (Ni)) does not affect the high levels of constitutive expression of TcYSL genes [60] (Gendre et al., 2007). We found that YSL-Eucgr.KO2319 was induced by AMF and was affected by changes in the $\mathrm{Zn}$ concentration, indicating that this gene may be involved in the transport of HM and homeostatic balance.

We performed Pearson's correlation analysis of genes in the YSL family and found that the transcript levels of YSL-Eucgr.K02319 and YSL-Eucgr.K02321 were highly significantly correlated $(R=0.924, P<0.001$; Supplementary Table. S4).

\section{ZIFL transporter family}

ZIFL genes are major facilitator superfamily (MFS) transporters that play roles in responding to different stresses, including $\mathrm{Zn}$ stress [61]. Since the identification of three ZIFL genes in Arabidopsis, referred to as AtZIF1 (AT5G13740), AtZIFL1 (AT5G13750), and AtZIFL2 (AT3G43790), evidence for their role in
Zn homeostasis has been accumulating [61]. ZIF1 is thought to be involved in the proton-coupled transport of metal chelators or metal-chelate complexes into vacuoles, as the ZIF1 protein contains conserved motifs for proton/substrate antiport and related proteins mostly transport organic molecules [62].

Eight candidate ZIFL family genes were identified in the E. grandis genome. To identify the evolutionary relationships between EgZIFL genes from different plant species, a phylogenetic tree was constructed with 35 ZIFL transport protein sequences from five plant species (Supplementary Fig. S14). Bioinformatics analyses showed that ZIFL genes were well conserved and had similar physicochemical properties. Conserved motif structures were also detected (Supplementary Fig. S15). And the chromosomal location of ZIFL gene family were shown in the chromosome-scale genome of E.grandis (Supplementary Fig. S16).

ZIFL genes were found to have different evolutionary histories in monocot and dicot lineages, which is consistent with the conclusions of Ricachenevsky et al. [63].

We analyzed the expression of EgZIFL genes with different $\mathrm{Zn}$ treatments, between mycorrhizal and nonmycorrhizal plants, and in response to different $\mathrm{Zn}$ concentration stresses. The data on the expression of EgZIFL genes under different $\mathrm{Zn}$ concentrations for NMand AMF-treated plants are shown in Fig. 4.

EgZIFL, AtZIF1, AtZIFL1, and PtZIFL2 were in a unified position on the evolutionary tree (Supplementary Fig. S14). The essential micronutrients Fe and $\mathrm{Zn}$ often limit plant growth but are toxic in excess. PtZIFL2 was predicted to have a typical conserved domain (MFS structure and zinc finger structure), indicating that it is a hydrophobic TM secreted protein with a TM transport function when $\mathrm{Zn}$ is in excess. Through subcellular localization prediction analysis, these four proteins in P. trichocarpa were localized to the plasma membrane, while AtZIF1 was localized to the vacuole membrane $[63,64]$. The AtZIF1 transporter is clearly involved in $\mathrm{Zn}$ homeostasis, as the loss-of-function atzif1 mutant has altered $\mathrm{Zn}$ distribution and its transcription is upregulated by excess $\mathrm{Zn}$ [65]. We found that ZIFL-Eucgr. G02630 was upregulated by a high $\mathrm{Zn}$ concentration (Fig. 4), which was consistent with the results of previous studies of this gene in Arabidopsis. This result indicates that ZIFL-Eucgr.G02630 may be involved in $\mathrm{Zn}$ homeostasis and may thus be related to HM resistance in Eucalyptus spp. After inoculation with AMF at a high $\mathrm{Zn}$ concentration, the expression level of ZIFL-Eucgr.G02630 decreased significantly, indicating that AMF is involved in maintaining a steady state of $\mathrm{Zn}$ to facilitate the resistance of Eucalyptus spp. to HMs. 


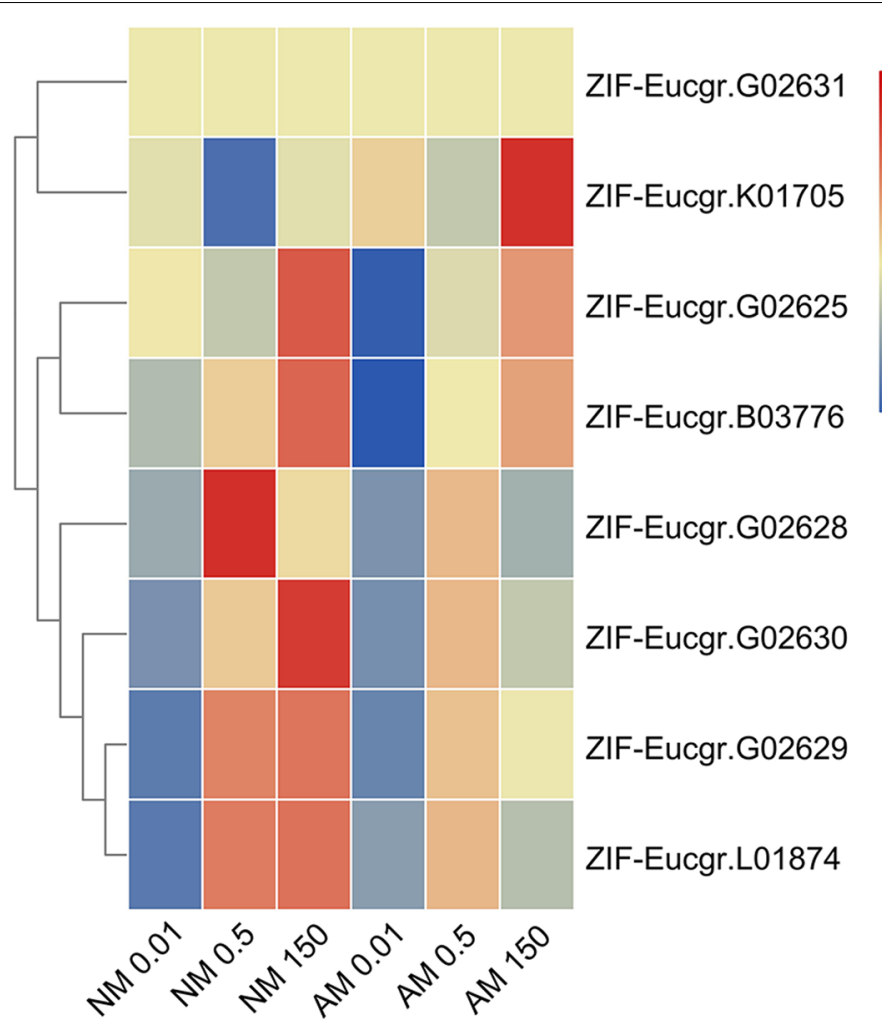

Fig. 4 Heatmap of ZIFL family members. Cluster analysis of transcriptional fold-changes of ZIFL family gens in roots of non-mycorrhizal and mycorrhizal E. grandis exposed to $0.01,0.5$, or $150 \mu \mathrm{M} \mathrm{ZnCl}_{2}$. The color scale indicates fold-changes of mRNAs. For each gene, the expression levels in non-mycorrhizal roots exposed to $0.5 \mu \mathrm{M} \mathrm{ZnCl}_{2}$ were defined as 1, and the corresponding fold-changes under 0.01 and $150 \mu \mathrm{M} \mathrm{ZnCl}_{2}$ were calculated

We performed Pearson's correlation analysis of the ZIFL family genes and found that the transcript levels of ZIFL-Eucgr.G02629 and ZIFL-Eucgr.L01874 $(R=0.829)$ were highly significantly correlated $(P<0.001$, Supplementary Table. S5).

\section{Transporters that remove metals from the cytosol HMA transport family}

HMAs are proteins that hydrolyze ATP and use the released energy for TM transport. They also transport $\mathrm{Zn}^{2}{ }^{+}, \mathrm{Cd}^{2+}, \mathrm{Pb}^{2}{ }^{+}, \mathrm{Cu}^{2+}$, and other heavy metal ions across the membrane. HMA proteins transport heavy metal ions selectively. They may play an important role in the phytoremediation of contaminated soil. HMA family members are grouped into two distinct clades in phylogenetic analyses [66]. Members of one clade play roles in $\mathrm{Cu}$ and silver $(\mathrm{Ag})$ transport, while members of the second clade function as $\mathrm{Zn} /$ cobalt $(\mathrm{Co}) / \mathrm{Cd} / \mathrm{Pb}$ transporters [67].

In roots, the abundance of HMA family gene transcripts was higher after NM treatment than after AMF treatment under low-Zn conditions, except for $H M A$ Eucgr.J00786 transcript levels, which were higher after
AMF treatment. Every member of the HMA gene family had lower transcript levels after AMF treatment than after NM treatment under high-Zn conditions (Fig. 5).

To identify the evolutionary relationships between $H M A$ genes of different plant species, a phylogenetic tree was constructed with 32 HMA transport protein sequences from 4 plant species (Supplementary Fig. S17). Bioinformatics analyses showed that HMA genes were well conserved and had similar physicochemical properties. Conserved motif structures were also detected (Supplementary Fig. S18). And the chromosomal location of HMA gene family were shown in the chromosome-scale genome of E.grandis (Supplementary Fig. S19).

HMA-Eucgr.C00131 and HMA-Eucgr.C02245 were found to be in the same branch of the phylogenetic tree as AtHMA2 and OsHMA2 (Supplementary Fig. S17). Therefore, these two genes are predicted to have the same function as members of the HMA2 subfamily. OsHMA2 plays a role in $\mathrm{Zn}$ and $\mathrm{Cd}$ loading to the xylem and participates in root-to-shoot translocation of these metals in rice [68]. Eren et al. [69] found that AtHMA2 is a high-affinity $\mathrm{Zn}$ transporter, transporting $\mathrm{Zn}$ out of cells to maintain a low $\mathrm{Zn}$ level in the cytoplasm and a 


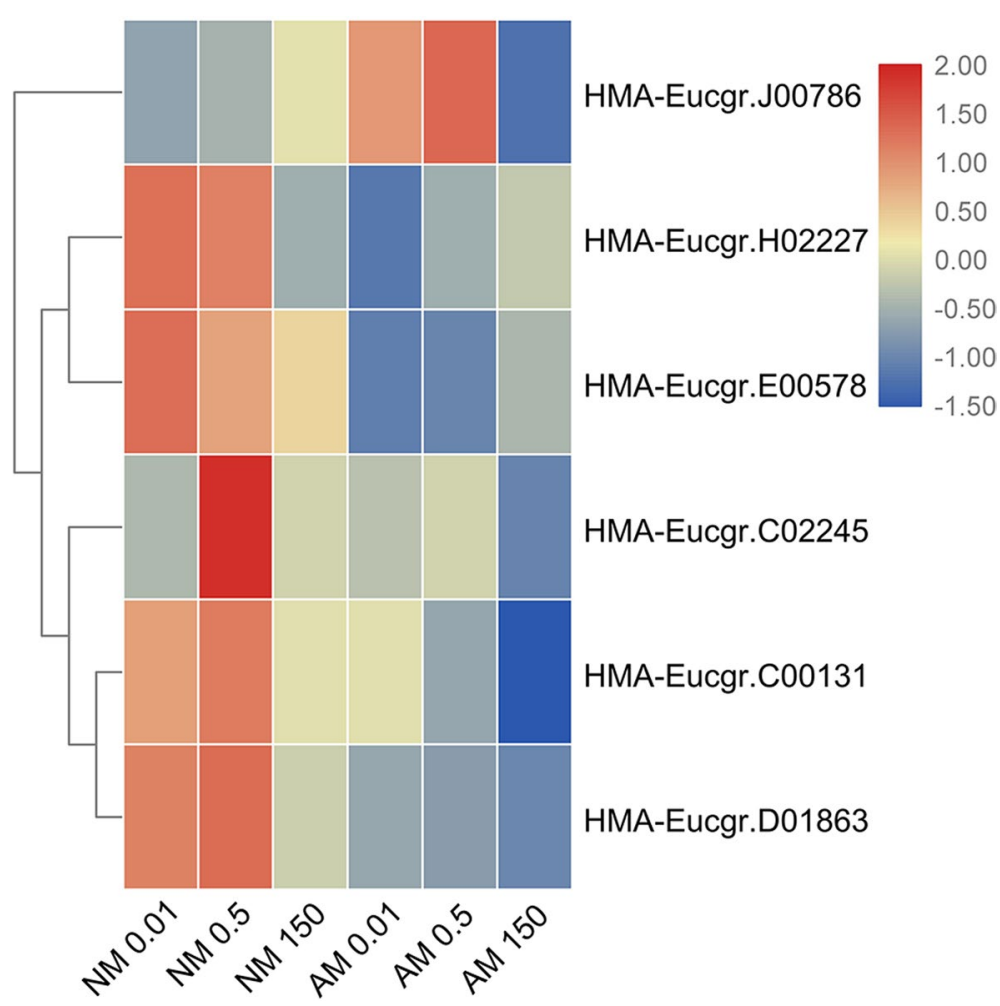

Fig. 5 Heatmap of HMA family members. Cluster analysis of transcriptional fold-changes of HMA family gens in roots of non-mycorrhizal and mycorrhizal E. grandis exposed to $0.01,0.5$, or $150 \mu \mathrm{M} \mathrm{ZnCl}_{2}$. The color scale indicates fold-changes of mRNAs. For each gene, the expression levels in non-mycorrhizal roots exposed to $0.5 \mu \mathrm{M} \mathrm{ZnCl}_{2}$ were defined as 1, and the corresponding fold-changes under 0.01 and $150 \mu \mathrm{M} \mathrm{ZnCl}_{2}$ were calculated

steady-state balance of $\mathrm{Zn}$ within cells. The pericycle plasma membrane protein AtHMA2 is responsible for loading $\mathrm{Zn}$ into the xylem, thus contributing to the control of the long-distance transport of $\mathrm{Zn}$ from roots to shoots [70]. The decrease in HMA-Eucgr.C00131 and HMA-Eucgr.C02245 gene expression levels under high$\mathrm{Zn}$ conditions decreased the accumulation of $\mathrm{Zn}$ in the roots of E. grandis. After inoculation with AMF under high- $\mathrm{Zn}$ conditions, the expression of these genes was significantly inhibited, which may be because AMF symbiosis directs HMs to the roots and HM transporters at the plasmalemma or tonoplast of both symbiotic partners may catalyze the export of HMs from the cytoplasm [71].

HMA-Eucgr.J00227, AtHMA1, and OsHMA1 were found to be in the same branch of the phylogenetic tree (Supplementary Fig. S17). OsHMA1 is highly upregulated by Zn deficiency in shoot tissue. OsHMA1 may play a role in $\mathrm{Zn}$ efflux from plastids and may contribute to detoxification in the presence of excess $\mathrm{Zn}$ [72]. AtHMA1 is located in the chloroplast envelope, where it contributes to $\mathrm{Zn}$ detoxification by reducing the $\mathrm{Zn}$ content in A. thaliana plastids under conditions of excess $\mathrm{Zn}$ [73]. Therefore, HMA-Eucgr.J00227 is considered to have a
$\mathrm{Zn}$ transport function, and its expression level decreased under high-Zn conditions. This may have been a result of $\mathrm{Zn}$ redistribution, indicating that this gene may have a detoxification function. After inoculation with AMF, HMs may bind to the cell wall and may be deposited in the vacuole of the fungus, which reduces the absorption of $\mathrm{Zn}$ by the plant. Thus, the expression level of this gene decreased after inoculation with AMF.

We found that HMA-Eucgr.J00786 was induced by a high $\mathrm{Zn}$ concentration (Fig. 5), which was consistent with the expression pattern of OsHMA9 (Supplementary Fig. S17). OsHMA9 localizes to the plasma membrane and can discharge heavy metals to the outside of the cell, which may play a role in HM detoxification [74]. After inoculation with AMF, the expression level of $H M A$ Eucgr.J00786 increased when the $\mathrm{Zn}$ concentration was low. The resulting promotion of $\mathrm{Zn}$ efflux from root cells then allows more $\mathrm{Zn}$ to be transported to the soil. The decrease in expression under high-Zn conditions may be due to the AM fungal absorption of $\mathrm{Zn}$ transported from plant cells.

We performed Pearson's correlation analysis of HMA family genes and found that the transcript levels of 
HMA-Eucgr.C00131 and HMA-Eucgr.D01863 were highly significantly correlated $(R=0.773, P<0.001$, Supplementary Table. S6).

\section{The cation efflux gene family}

The CE gene family, also known as the cation diffusion facilitator gene family, was first described by Nies and Silver [75] and is considered to be compatible with $\mathrm{Zn}^{2+}$, $\mathrm{Cd}^{2+}, \mathrm{Co}^{2+}$, and $\mathrm{Ni}^{2+}$ transport. Members of this family are associated with the HM tolerance of plants. Most CE transporters are involved in storing metal ions within cells and transporting metal ions out of cells [76]. Many CE gene family members have been identified, and they have certain common structural features, including a C-terminal cation-binding domain, an $\mathrm{N}$-terminal signal peptide sequence, and approximately six TM domains. The TM domains TM4-TM5 in CE family members in eukaryotes are all rich in histidine [77]. Most of the CE proteins are located in the cell membrane, but some are located in intracellular membrane systems, such as vacuole membranes and Golgi membranes.
To identify the evolutionary relationships between $C E$ genes of different plant species, a phylogenetic tree was constructed with $44 \mathrm{CE}$ transport protein sequences from 6 plant species (Supplementary Fig. S20). Bioinformatics analyses showed that $\mathrm{CE}$ genes were well conserved and had similar physicochemical properties. Conserved motif structures were also detected (Supplementary Fig. S21). And the chromosomal location of CE/MTP gene family were shown in the chromosome-scale genome of E.grandis (Supplementary Fig. S22).

Fourteen CE transporters were identified in the $E$. grandis genome based on sequencing results. Cluster analysis of transcript levels of the CE gene family clearly separated root samples from NM- and AMF-treated plants based on their responsiveness to $\mathrm{Zn}$ concentrations. According to variations in their transcript levels, they were divided into two subclusters. The two subclusters were distinguished by changes induced by AMF inoculation at a high Zn concentration (Fig. 6).

We found that CE-Eucgr.E01084, CE-Eucgr.E01089, and CE-Eucgr.E01088 were highly homologous and were in the same branch of the phylogenetic tree as OsMTP1,

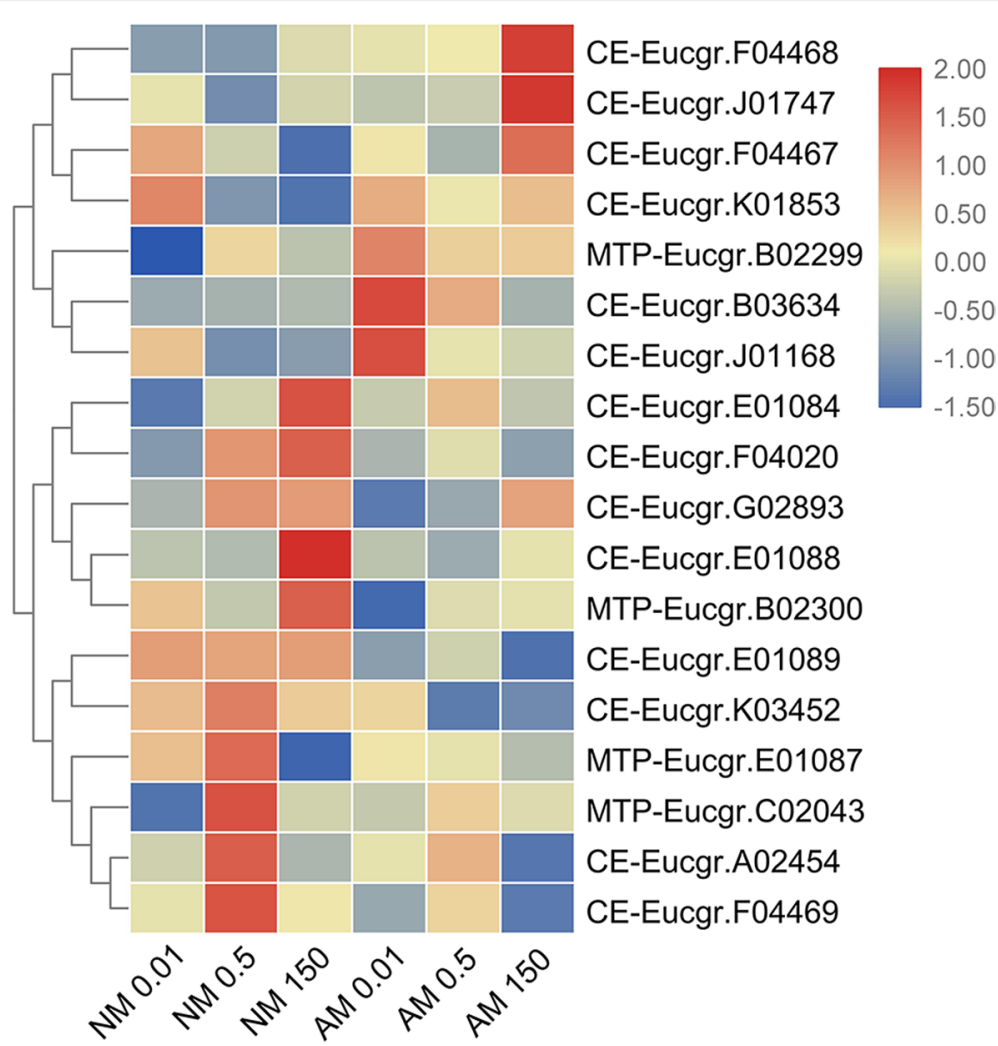

Fig. 6 Heatmap of CE family members. Cluster analysis of transcriptional fold-changes of CE family gens in roots of non-mycorrhizal and mycorrhizal E. grandis exposed to $0.01,0.5$, or $150 \mu \mathrm{M} \mathrm{ZnCl}_{2}$. The color scale indicates fold-changes of mRNAs. For each gene, the expression levels in non-mycorrhizal roots exposed to $0.5 \mu \mathrm{M} \mathrm{ZnCl}_{2}$ were defined as 1, and the corresponding fold-changes under 0.01 and $150 \mu \mathrm{M} \mathrm{ZnCl}_{2}$ were calculated 
AtMTP1, AtMTP3, MtMTP1, and MtMTP3 (Supplementary Fig. S20). AtMTP3 and AtMTP1 are mainly expressed in the roots of $A$. thaliana. They transfer excess $\mathrm{Zn}$ from the cytoplasm to the vacuole and reduce the transport of $\mathrm{Zn}$ from the roots to the shoots [78]. We found that CE-Eucgr.E01088 and CE-Eucgr.E01084 transcript levels were upregulated after NM treatment under high-Zn conditions (Fig. 6), indicating that these two genes may have a similar function to AtMTP3 in Arabidopsis (Supplementary Fig. S20), which transports excess $\mathrm{Zn}$ to the vacuoles in the roots. We conclude that $C E$ Eucgr.E01088 and CE-Eucgr.E01084 play crucial roles in avoiding $\mathrm{Zn}$ stress in the root meristematic tissue before the activation of $\mathrm{Zn}$ export systems and the synthesis of phytochelatins. After inoculation with AMF under high$\mathrm{Zn}$ conditions, the transcriptional levels of CE-Eucgr. E01084, CE-Eucgr.E01089, and CE-Eucgr.E01088 were suppressed. This may be because the mycelium increased $\mathrm{Zn}$ absorption under high- $\mathrm{Zn}$ conditions, resulting in the adsorption of more $\mathrm{Zn}$ to the cell wall of mycorrhizal fungi, thus reducing the absorption of $\mathrm{Zn}$ by plants [79].

We found that CE-Eucgr.J01168 was highly homologous to AtMTP11 (Supplementary Fig. S20). Eucgr. J01168 had the highest transcriptional level at a low $\mathrm{Zn}$ concentration and the transcript levels of these genes were higher after AMF treatment than after NM treatment (Fig. 6). AtMTP11 is involved in the tolerance of A. thaliana to high Mn concentrations. It is localized to the Golgi apparatus and is thought to remove $\mathrm{Mn}$ from the cell via the exocytosis of secretory vesicles [80]. OsMTP11 is a trans-Golgi network-localized Mn transporter that is required for $\mathrm{Mn}$ homeostasis and contributes to the Mn tolerance of rice [81]. Therefore, we predicted that Eucgr.J01168 may also be located in the Golgi apparatus. It was induced under low-Zn conditions and promoted the transport of $\mathrm{Zn}$ to the shoots, whereas under high-Zn conditions, it may be transported out of cells, thereby playing a role in cellular metal homeostasis.

We performed Pearson's correlation analysis of CE/ MTP family genes and found that the transcript levels of CE-Eucgr.F04469 and CE-Eucgr.A02454 $(R=0.849)$, CE-Eucgr.J01747 and CE-Eucgr.F04468 $(R=0.764)$, and CE-Eucgr.K01853 and CE-Eucgr.F04020 $(R=0.762)$ were highly significantly correlated $(P<0.001$, Supplementary Table. S7).

\section{Improved metal tolerance through changes in nutrients Phosphorus transporter genes}

Phosphorus is an essential element for plants. It is involved in the synthesis of nucleic acids and ATP in cells, as well as the regulation of enzyme activity and signal transduction [82]. Pi is relatively inaccessible to plant roots because of its low solubility and high capacity for adsorption to soil particles. Plants must, therefore, use a complex series of Pi transporters to acquire Pi from the soil and distribute it to tissues and subcellular organelles. $\mathrm{Pi}$ acquisition at the root periphery in plants is coupled with proton entry ( $\mathrm{Pi}: \mathrm{H}^{+}$symporter) and mediated by members of the PHT1 gene family [83].

Pi-deficient plants over-accumulate $\mathrm{Zn}$ in the shoots and, conversely, Zn-deficient plants overaccumulate $\mathrm{Pi}$ in the shoots [28]. More than $90 \%$ of land plants form symbiotic associations with mycorrhizal fungi [83]. Mycorrhizae play an important role in the acquisition of $\mathrm{P}$ by the plant [29] and also facilitate $\mathrm{Zn}$ transport in the soilfungi-plant continuum [19].

Thirty-five candidate PHT family genes were identified in the E. grandis genome. Bioinformatics analyses showed that PHT genes were well conserved and had similar physicochemical properties. Conserved motif structures were also detected (Supplementary Fig. S23). And the chromosomal location of PHT gene family were shown in the chromosome-scale genome of E.grandis (Supplementary Fig. S24). Through a heatmap analysis, we found that PT-Eucgr.A02668, PT-Eucgr.K00323, and PT-Eucgr.J00101 were only expressed after inoculation with AMF. The expression levels of these genes were significantly reduced by a high $\mathrm{Zn}$ concentration. The expression level of PT-Eucgr.A02668 was also reduced by a low $\mathrm{Zn}$ concentration. However, the expression levels of PT-Eucgr.F03590, PT-Eucgr.I01609, and PT-Eucgr. H03069 increased significantly after inoculation with AMF under high-Zn conditions. Moreover, PT-Eucgr. F03590 and PT-Eucgr.H03069 expression levels were affected by NM treatment under low- $\mathrm{Zn}$ conditions (Supplementary Fig. S25).

PT-Eucgr.A02668, PT-Eucgr.K00323, and PT-Eucgr. J00101 showed homology with MtPT4 and OsPT11 (Supplementary Fig. S26). MtPT4 of Medicago truncatula and OsPT11 of Oryza sativa are localized in the perarbuscular membrane [84, 85]. Moreover, MtPT4 RNAi lines and loss-of-function mutants fail to show symbiosisassociated increases in $\mathrm{Pi}$ or growth responses, indicating that MtPT4 is required for Pi transport in the symbiotic system [86]. These data indicate that these three genes are phosphorus transporters specifically induced by mycorrhizal fungi and that they are affected by the $\mathrm{Zn}$ concentration.

PT-Eucgr.F03590, PT-Eucgr.I01609, and PT-Eucgr. H03069 showed homology with LePT2 and MtPT2 (Supplementary Fig. S26). Expression of these genes was induced under high-zinc conditions and increased after inoculation with AMF. The expression levels of PT-Eucgr.F03590 and PT-Eucgr.H03069 increased after NM treatment under low-Zn conditions. This result shows that after inoculation with AMF, the absorption 
of phosphorus is increased to reduce the toxic effect of heavy metals. PT-Eucgr.H03067 also showed homology with LePT2 and MtPT2. However, PT-Eucgr.H03067 levels increased under high-Zn conditions after NM treatment and after inoculation with AMF; however, under these conditions, the expression levels were lower than those observed after NM treatment under low-Zn and high-Zn conditions. LePT2 is predominantly expressed in Pi-deficient roots and is significantly downregulated in mycorrhizal roots under low-Pi conditions [87]. Therefore, in this sub-branch, the Eucalyptus PHT gene has evolved two functions to cope with the effects of changes in $\mathrm{Zn}$ concentration. The expression levels of MtPT2 within mycorrhizal roots are likely influenced by changes in the $\mathrm{Zn}$ status of the plant as a result of symbiotic function, as expression levels in the roots are inversely correlated with the P status of mycorrhizal plants [54].

We performed Pearson's correlation analysis on PHT family genes and found that the transcript levels of $P H T$ Eucgr.H03069 and PHT-Eucgr.F03590 $(R=0.894)$ and PHT-Eucgr.H03069 and PHTEucgr.I01609 $(R=0.861)$ were highly significantly correlated $(P<0.001$, Supplementary Table. S8).

\section{AMTs and NRTs}

Plants absorb and utilize two inorganic nitrogen sources, ammonium nitrogen $\left(\mathrm{NH}_{4}{ }^{+}\right)$and nitrate nitrogen $\left(\mathrm{NO}_{3}{ }^{-}\right)$ [88]. The NRT family is responsible for transporting $\mathrm{NO}_{3}{ }^{-}$and the AMT family is responsible for transporting $\mathrm{NH}_{4}^{+}[89,90]$.

Fourteen AMTs and eleven NRTs were identified in the $E$. grandis genome based on the sequencing results. Bioinformatics analyses showed that AMTs and NRTs were well conserved and had similar physicochemical properties. Conserved motif structures were also detected (Supplementary Fig. S27). And the chromosomal location of AMT and NRT gene family were shown in the chromosome-scale genome of E.grandis (Supplementary Fig. S28).

The expression levels of NRT-Eucgr.H02533 decreased with increasing $\mathrm{Zn}$ concentration under NM treatment conditions, and its expression levels increased significantly after inoculation with AMF under high-Zn conditions. Based on the heat map, AMT-Eucgr.K01403 and AMT-Eucgr.K03320 are AMTs that are specifically induced by mycorrhizal fungi, as their expression levels decreased significantly after inoculation with AMF (Supplementary Fig. S29). Zn deficiency reduces the nitrogen content in the root system and increases the non-protein nitrogen content, which mainly affects RNA metabolism and consequently protein synthesis. The large accumulation of free amino acids, regardless of $\mathrm{Zn}$ content, causes a decrease in the levels of ammonium nitrogen and nitrate nitrogen [91]. Thus, $\mathrm{N}$ is critical for the uptake and accumulation of $\mathrm{Zn}$ in plants, and it deserves special attention in the biofortification of food crops with $\mathrm{Zn}$ [92].

We found that the expression levels of AMT family genes were decreased by a high $\mathrm{Zn}$ concentration and increased significantly after AMF inoculation. However, AMT gene expression levels induced by a low Zn concentration increased after inoculation with AMF, indicating that AMTs play roles in symbiosis with AMF at low $\mathrm{Zn}$ concentrations. Thus, nutrient absorption plays a role in improving the resistance of plants to high $\mathrm{Zn}$ concentrations.

We performed Pearson's correlation analysis of genes in the AMT and NRT families and found that the transcript levels of AMT-Eucgr.B02160 and AMT-Eucgr.L03045, AMT-Eucgr.C01787 and AMT-Eucgr.H05067, and AMTEucgr.I02296 and AMT-Eucgr.K03320 were highly significantly correlated $(P<0.001$, Supplementary Table. S9).

\section{Potassium transporters}

Potassium transporters are important for potassium uptake by plants. Based on their protein structure and function, they can be divided into the $\mathrm{K}^{+}$uptake permease (KUP)/high-affinity $\mathrm{K}^{+}$(HAK)/KT family, the HKT family, and the cation/proton antiporter (CPA) family, all of which are expressed in different plant tissues or organs. Cation and $\mathrm{pH}$ homoeostasis is regulated by monovalent CPAs that fall into two categories, the CPA1 family, which includes $\mathrm{Na}^{+} / \mathrm{H}^{+} \mathrm{NHX}$ antiporters, and the CPA2 family, which includes cation $/ \mathrm{H}^{+}(\mathrm{CHX})$ and $\mathrm{K}^{+}$ efflux antiporters (KEAs) [93].

Fifty-six candidate potassium transporter genes were identified in the E. grandis genome. Among them, the $\mathrm{KUP} / \mathrm{HAK} / \mathrm{KT}$ family was predicted to have $30 \mathrm{mem}$ bers (KTs: 4, HAKs: 23, CHXs: 23), and the CPA family was predicted to have 22 members (CHXs: 17, KEAs: 4, NHXs: 1). Bioinformatics analyses showed that subfamily of potassium transporters were well conserved and had similar physicochemical properties of each subfamily. Each subfamily conserved motif structures were also detected (Supplementary Fig. S30). And the chromosomal location of potassium transporters gene family were shown in the chromosome-scale genome of E.grandis (Supplementary Fig. S31). According to the heat map, 9 genes were induced by $\mathrm{Zn}$ and mycorrhizae (KTs: 1, KUPs: 2; HAKs: 4; CHXs: 2) (Supplementary Fig. S32).

A high $\mathrm{Zn}$ concentration reduced the levels of $H A K$ Eucgr.C02191, HAK-Eucgr.C00265, and HAK-Eucgr. G02011 transcripts in NM-treated roots. AMF colonization increased the levels of HAK-Eucgr.C02191 transcripts and reduced the levels of HAK-Eucgr.C00265 
and HAK-Eucgr.G02011 transcripts. However, a high $\mathrm{Zn}$ concentration increased the levels of HAK-Eucgr. F02234, NHX-Eucgr.F00635, and HAK-Eucgr.G01991 transcripts. Moreover, AMF colonization increased the levels of HAK-Eucgr.F02234 transcripts and reduced the levels of HAK-Eucgr.G01991 and NHXEucgr.F00635 transcripts (Supplementary Fig. S32).

Many previous studies have found that certain physiological processes that are important for plant growth, such as cell stretching and shock motion, are also related to the regulation of potassium ions in plants to maintain cell turgor and osmotic potential [94]. In summary, the effect of potassium ions on the regulation of plant cell turgor and osmotic potential has important physiological significance in the normal growth and development of plants.

We performed Pearson's correlation analysis of potassium transporter genes and found that the transcript levels of KT-Eucgr.C04163 and KUP-Eucgr. B03355 ( $R=0.821)$, KUP-Eucgr.B03355 and KT-Eucgr. C04163 $(R=0.821)$, KUP-Eucgr.B03355 and HAKEucgr.C02265 $(R=0.744), \quad$ KUP-Eucgr.B03355 and HAK-Eucgr.G02011 $(R=0.889), \quad$ KUP-Eucgr.B03355 and CHX-Eucgr.K03153 $(R=0.750)$, HAK-Eucgr. C02265 and HAK-Eucgr.G02011 $(R=0.747), H A K-$ Eucgr.C02265 and CHXEucgr.E00818 $(R=0.861)$, HAK-Eucgr.C02265 and CHXEucgr.K03153 $(R=0.939)$, CHXEucgr.E00818 and HAK-Eucgr.G02011 $(R=0.733)$, and CHXEucgr.E00818 and CHXEucgr.K03153 $(R=0.771)$ were highly significantly correlated $(P<0.001$, Supplementary Table. S10).

\section{PCA of heavy metal transporter and nutrient transporter responses}

A PCA was performed using the data of related genes involved in HM and nutrient responses. In the PCA plot, a greater distance between symbols associated with $\mathrm{Zn}$ concentration suggested a stronger responsiveness of $\mathrm{HM}$ and nutrient transporters to changes in $\mathrm{Zn}$ concentration. The results of the PCA indicated that nutrient-related transporters were clustered together, but separately in AMF- and NM-treatment groups, at different $\mathrm{Zn}$ concentrations, indicating that AMF symbiosis may improves the metal stress resistance of plants mainly through nutrient regulation (Fig. 7).

\section{Conclusions}

In the presence of symbiosis with AMF, we explored the variation in the transcription levels of six HM-related gene families under high-Zn conditions. The results indicated that the expression levels of one $Z N T$ gene, three $Y S L$ genes, and one $C O P T$ gene were significantly upregulated, while those of one ZIFL gene and one Ctr gene were significantly downregulated $(p<0.05)$.

Under high-Zn conditions, genes related to the absorption of nutrients, mainly $\mathrm{N}, \mathrm{P}$, and $\mathrm{K}$, were analyzed. We found that the expression levels of two NRT2 transporter genes, and one $H A K$ transporter gene were significantly downregulated $(p<0.05)$. There was no significant upregulation of nutrient-related genes, indicating that a high $\mathrm{Zn}$ concentration inhibits the growth and development of plants. Meanwhile, under AMF symbiosis and high-Zn conditions, the expression levels of seven $P H T$ genes, one NRT1 gene, two NRT2 genes, one HAK gene, and three $A M T$ genes were significantly upregulated $(p<0.05)$, whereas those of only one PHT gene and one NRT1 gene were significantly downregulated $(p<0.05)$ (Fig. 8).

Here, we showed that AMF increases the resistance of E. grandis to high-Zn stress by improving the absorption of nutrients by the plant and regulating $\mathrm{Zn}$ uptake at the gene transcription level. Among theses genes, 41 heavy metal transporters (ZNT:15, YSL:11, COPT/Ctr:8, CE/ MTP:3, ZIFL:4) and 36 nutrition-related transporters are involved in $\mathrm{Zn}$ tolerance in $E$. grandis with AMF symbiosis. Although these genes' function was inferred from their homologous genes' function in model herbaceous plants, these candidate genes' multiple function still need to be investigated at whole plant and tissue level for the woody perennial plants having unique physiological and anatomical structure. Futhermore, the interaction between HM tolerance and nutrient acquisition should be furtherly explored to facilitate the genetic improvement of nutrient utilization in E. grandis at the HM-contaminated areas.

\section{Materials and methods \\ Plant cultivation, inoculation, and $\mathrm{Zn}$ treatment}

The seedlings needed for the experiment were taken from E. grandis clone GL1, kindly provided by Dr. Chunjie Fan from the Research Institute of Tropical Forestry, Chinese Academy of Forestry, Guangzhou, China. The AMF species Rhizophagus irregularis (BGCBJ09) was purchased from the Beijing Academy of Agriculture and Forestry Sciences (Beijing, China). The AMF was propagated using Trifolium

(See figure on next page.)

Fig. 7 Principal component analysis (PCA) plot of the first two principal components in roots of non-mycorrhizal and mycorrhizal E. grandis. The analysis was conducted using data of heavy metal-related and nutrition-related transporters of non-mycorrhizal and mycorrhizal E. grandis exposed to $0.01,0.5150 \mathrm{MM} \mathrm{ZnCl}_{2}$. (a) Heavy metal related transporters (b) Nutrition-related transporters (c) Heavy metal-related and nutrition-related transporters 
(a)

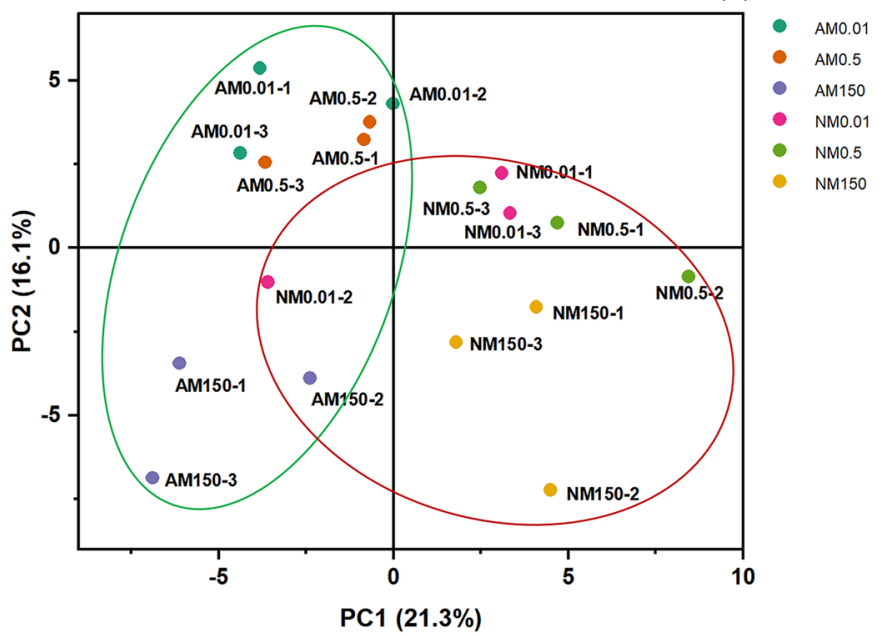

(b)

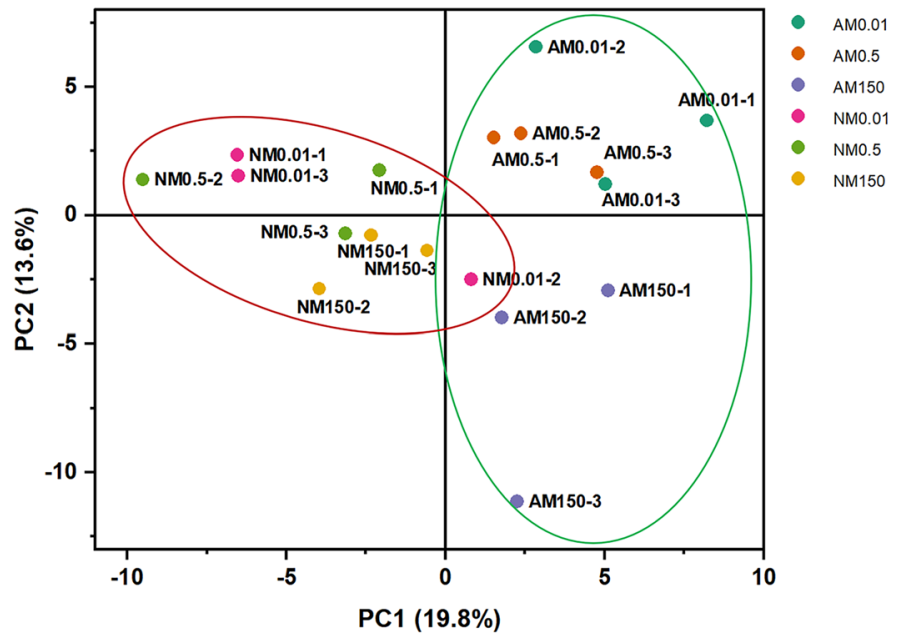

(c)

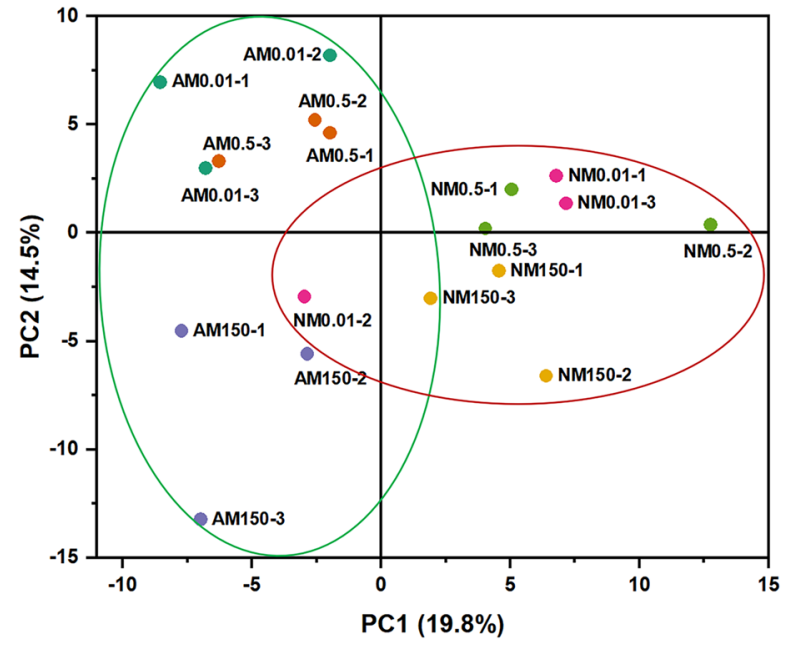

Fig. 7 (See legend on previous page.) 


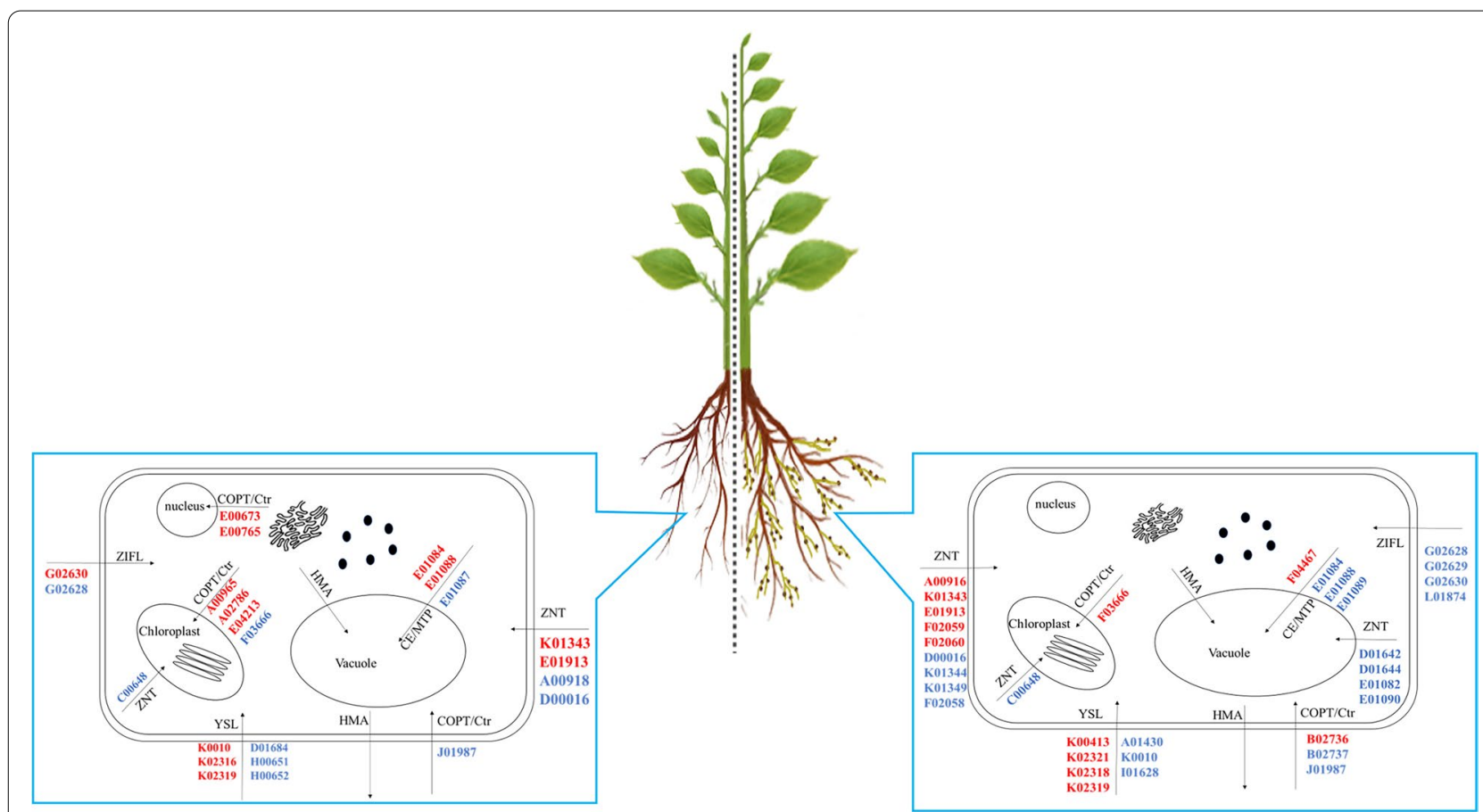

Fig. 8 Graphical representation of plant responses to zinc ( $Z n$ ) excess and resupply of $Z n$ in uptake and translocation of $Z n$ and the expression of the Heavy metal transporter in E. grandis. Blue arrows, increased levels; red arrows, reduced levels

repens, and the inoculum was collected to obtain spores. The AMF spores were obtained by sucrose-gradient centrifugation [95]. Uniform E. grandis seedlings were selected and transplanted into plastic pots $(9 \mathrm{~cm}$ high, $10 \mathrm{~cm}$ diameter $)$ with sterile medium (quartz sand:vermiculite, $\mathrm{V}: \mathrm{V}=2: 1$ ). Seedlings receiving inoculation treatment (hereafter referred to as the AMF-treatment group) were inoculated with 600 spores, which were added to the medium in each pot. Seedlings in the non-inoculation group were not inoculated with AMF spores (referred to as the NM-treatment group).

Plants were grown in a growth chamber with $25 / 20^{\circ} \mathrm{C}$ day/night temperatures, $60 \%$ relative humidity, and a 16/8-h light/dark photoperiod. To generate highly colonized roots, for 45 days post-inoculation (dpi), the plants were supplied with $50 \mathrm{~mL}$ of Long-Ashton solution [96] with a modified monosodium phosphate $\left(\mathrm{NaH}_{2} \mathrm{PO}_{4}\right)$ concentration $(30 \mu \mathrm{M})$ every 3 days. This

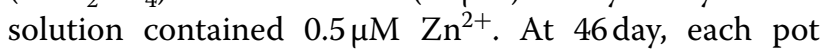
was immersed in a beaker filled with distilled water. The water was changed five times, once every $2 \mathrm{~h}$, to remove residual nutrients from the substrates. The AMF- and $\mathrm{NM}$-treatment groups were then divided into three subgroups: low $\mathrm{Zn}$ concentration $(0.01 \mu \mathrm{M} \mathrm{Zn}$ supplied as $\left.\mathrm{ZnCl}_{2}\right)$, normal $\mathrm{Zn}$ concentration $(0.5 \mu \mathrm{M} \mathrm{Zn}$ supplied as $\left.\mathrm{ZnCl}_{2}\right)$, and high $\mathrm{Zn}$ concentration $(150 \mu \mathrm{M} \mathrm{Zn}$ supplied as $\mathrm{ZnCl}_{2}$ ). Zinc treatment were supplied with $50 \mathrm{~mL}$ of Long-Ashton solution with different $\mathrm{Zn}$ concentration every three days for fifteen days, five times in total. There were six pots (replicates) for each $\mathrm{Zn}$ treatment.

\section{Arbuscular mycorrhizal colonization rate measurement} Mycorrhizal-colonized roots were stained with Wheat germ agglutinin-conjugated Alexa Fluor ${ }^{\circledR} 488$ (WGAAF488) as described previously [97]. Briefly, harvested roots were placed in $50 \%$ ethanol for more than $4 \mathrm{~h}$ and then transferred to $20 \%(\mathrm{w} / \mathrm{v}) \mathrm{KOH}$ for 2-3 days, followed by $0.1 \mathrm{M} \mathrm{HCl}$ for $2 \mathrm{~h}$ at room temperature. After removing the $\mathrm{HCl}$, the samples were rinsed twice with distilled water and once with phosphate-buffered saline (PBS, pH7.4), and then immersed in PBS/WGA-Alexa Fluor 488 staining solution $(0.2 \mu \mathrm{g} / \mathrm{mL})$ in the dark for more than $6 \mathrm{~h}$ at $37^{\circ} \mathrm{C}$. The arbuscular mycorrhizal colonization rate was determined under a fluorescence microscope (NIKON, Eclipse Ni-U) using the gridline intersect method described by Giovannetti and Mosses (2010).

\section{Acid digestion and determination of $\mathrm{Zn}$ and inorganic phosphate (Pi) content}

Dried leaves and roots were ground and digested $(50 \mathrm{mg})$ for $8 \mathrm{~h}$ in $5 \mathrm{~mL}$ of $6 \mathrm{M}$ nitric acid $\left(\mathrm{HNO}_{3}\right)$ in closed-glass tubes on heating blocks at $90^{\circ} \mathrm{C}$ [98]. Extracts were diluted in a solution of $2 \% \mathrm{HNO}_{3}$. Pi and Zn concentrations were determined by inductively coupled plasma mass spectrometry (Thermo Scientific ${ }^{\mathrm{TM}}$ 
iCAP $^{\mathrm{TM}}$ Q ICP-MS; Thermo Fisher Scientific, Waltham, MA, USA).

\section{cDNA library construction and sequencing}

Total RNA was extracted from individual samples using the RNAprep Pure Plant Kit (Tiangen, Beijing, China). For roots from each subgroup, three independent biological replicates were analyzed. RNA quality and concentration were determined by $1 \%$ agarose gel electrophoresis and spectrophotometry, respectively. mRNA was purified from total RNA using the TruSeq RNA Sample Prep Kit (Illumina, San Diego, CA, USA) with oligo-dT magnetic beads. mRNA samples were fragmented into 150-bp fragments using a chemical reagent at high temperature. Double-stranded cDNA was synthesized using random hexamer primers and end-repaired with an exonuclease and a polymerase. The cDNA fragments and sequencing adapters were ligated with T4 DNA ligase (Thermo Scientific), according to the manufacturer's protocol, and sequenced using an Illumina $\mathrm{HiSeq}^{\mathrm{TM}} 2000$ sequencing system.

\section{Transcriptome assembly}

Raw data (raw reads) were first processed using in-house Perl scripts. Clean data (clean reads) were obtained by removing reads containing adapter sequences, poly-Ns, and low-quality reads from the raw data. Meanwhile, the number of bases scoring Q20 and Q30, the GC content, and the sequence duplication level of the clean data were calculated.. All downstream analyses were based on clean data of high quality. Transcriptome assembly was accomplished using Trinity with min_kmer_cov set to 2 and all other parameters set to default values [99].

\section{Gene annotation}

Gene functional annotation was performed by sequence comparison with public databases. The Basic Local Alignment Search Tool was used to search for homology ( $E$ value $<0.00001$ ) between unique sequences and JGI nonredundant proteins (https://phytozome.jgi.doe. gov/pz/portal.html\#!!info?alias=Org_Egrandis), and Swiss-Prot (http://www.expasy.ch/sprot) databases were searched for protein sequence analysis. The best-hit transcripts were selected as unigenes. The Blast2GO program was then used to obtain Gene Ontology (GO) annotations and functional classification of all unigenes [100]. Enzyme Commission terms and biochemical pathway information were generated using Kyoto Encyclopedia of Genes and Genomes (KEGG) (http://www.genome.jp/ kegg/). Evolutionary genealogy of genes: Non-supervised Orthologous Groups (eggNOG) (http://eggnog.embl.de/) was used to predict and classify potential functions based on known orthologous gene products [101].

\section{Gene expression, signaling pathway analysis, and differential gene identification}

Based on the number of reads mapping to a particular gene, the reads per kilobase per million reads (RPKM) metric was used to estimate the transcript levels of the genes [102]. Briefly, the RPKM value was calculated by dividing the number of reads mapped to each gene by the length of the gene and the number of reads from the library to compensate for slightly different read depths for different samples. An RPKM threshold value of 0.1 was set to detect the presence of a unigene, which corresponds to a false discovery rate (FDR) of 5\% [103].

The DESeq program (http://www-huber.embl.de/users/ anders/DESeq/) was used for the statistical analysis of differentially expressed genes (DEGs) between two samples [104]. DEGs were identified according to a difference in expression $>$ two-fold and a significant $p$-value (padj $<0.05$ ), after adjusting for the FDR due to multiple testing procedures to minimize the chance of a type I error [105]. GO and KEGG analyses were also used to evaluate DEGs in a variety of biological pathways. Based on information from $\mathrm{Nr}$ (Non-Redundant Protein Sequence Database), eggNOG, GO, and KEGG analyses, DEGs involved in metamorphosis, immunity, and sensory perception were further investigated manually. The KEGG metabolic pathways for all unigenes with $\mathrm{GO}$ terms were constructed using an online tool with different colors to indicate different gene expression levels (http://www.genome.jp/kegg/tool/map_ pathway2.html). Functional domain analysis was performed using ExPASy PROSITE (http://www.expasy.ch/ tools/scanprosite/).

\section{Data analyses}

Gene families related to the transport and distribution of metals and nutrients in plants were selected for further analysis. These included zinc transporter (ZNT), copper transporter (COPT), zinc-induced facilitator (ZIF), yellow stripe-like (YSL), heavy metal ATPase (HMA), cation efflux (CE), phosphate transporter (PHT), ammonium transporter (AMT), nitrate transporter (NRT), and potassium transporter gene families. A cluster analysis of the transcriptional levels of these gene families was performed using TBtools (gitub. com/CJ-chen/TBtools). Phylogenetic analyses of each gene family were performed using the neighbor-joining method implemented in MEGA 6 (www.megasoftware. net). For principal component analysis (PCA), data were 
standardized and computed using Origin2021b (https:// www.originlab.com/). Pearson's correlation analyses were performed using SPSS (IBM, Armonk, NY, USA).

\section{Supplementary Information}

The online version contains supplementary material available at https://doi. org/10.1186/s12870-022-03456-5.

Additional file 1: Table S1. General information of ZNT transporter genes identified in Eucalyptus grandis. Table S2. Pearson's correlation analysis on ZNT family genes. Table S3. Pearson's correlation analysis on COPT/Ctr family genes. Table S4. Pearson's correlation analysis on YSL family genes. Table S5. Pearson's correlation analysis on ZIFL family genes. Table S6. Pearson's correlation analysis on HMA family genes. Table S7. Pearson's correlation analysis on CE/MTP family genes. Table S8. Pearson's correlation analysis on PHT family genes. Table $\mathbf{S 9}$. Pearson's correlation analysis on AMT and NRT family genes. Table S10. Pearson's correlation analysis on Potassium transporters family genes.

Additional file 2.

Additional file 3.

Additional file 4.

Additional file 5.

\section{Acknowledgements}

We thank Dr. Chunjie Fan (Research Institute of Tropical Forestry, Chinese Academy of Forestry, Guangzhou, China) for providing the Eucalyptus material, Ping Luo for technical assistance, and we are very grateful to Yuqiao Su and Wenzhen Lai for their helpful suggestions and their valuable comments on the early manuscript.

\section{Authors' contributions}

XW, W H and M T conceived and designed the paper; XW, $\mathrm{L}, \mathrm{ZL}, \mathrm{L}$ $H$,collected and analyzed the literature; $J L$ and $Y K$ drafted the paper and prepared the figures; $X X$ and $\mathrm{HC}$, have revised the manuscript. All authors have read and approved the final version of the manuscript.

\section{Funding}

This study was financially supported by the Laboratory of Lingnan Modern Agriculture Project, grant number (NZ2021025), the Key Projects of Guangzhou Science and Technology Plan (201904020022) and the National Natural Science Foundation of China (32001289).

\section{Availability of data and materials}

The datasets supporting the conclusion of this article are included within the article and its additional files, all gene expression data were deposited in Box (https://app.box.com/s/2a1z0u7pekdpk8cnoa43h6fcpmh2f45b) and Galaxy Project (https://usegalaxy.org/datasets/bbd44e69cb8906b568ca 01481728cd72/display?to_ext=tabular) and Eucalyptus grandis reference genome from Phytozome database (https://phytozome.jgi.doe.gov/pz/ portal.html\#!info?alias=Org_Egrandis), as well as can be requested from HWT (hwt@scau.edu.cn).

\section{Declarations}

\section{Ethics approval and consent to participate}

The data collection of plants and fungi were carried out with permission of related institution, and complied with national or international guidelines and legislation.

\section{Consent for publication}

Not applicable as the manuscript contains no individual identifying data.

\section{Competing interests}

The authors declare that they have no competing interests.

Received: 7 September 2021 Accepted: 4 February 2022

Published online: 22 February 2022

\section{References}

1. Philip W, Paula P, Claire S, Jacqueline T, Gladys W. Limits to the biofortification of leafy brassicas with zinc. Agric. 2018;8(3):32.

2. Lebeau T, Braud A, Jézéquel K. Performance of bioaugmentationassisted phytoextraction applied to metal contaminated soils: a review. Environ Pollut. 2008;153(3):497-522.

3. Johnston T, Datta R, Sarkar D. Phytoextraction and Phytostabilization: Technical, Economic and Regulatory Considerations of the Soil-Lead Issue. In: Lehr JH, Keeley J, editors. Water Encyclopedia; 2005. https:// doi.org/10.1002/047147844X.gw851.

4. Brown SL, Chaney RL, Angle JS, Baker A. Phytoremediation potential of Thlaspi caerulescens and Bladder Campion for zinc- and cadmiumcontaminated soil. J Environ Qual. 1994;23(6):1151-7.

5. Blaylock MJ, Salt DE, Dushenkow S. Enhanced accumulation of Pb in Indian mustard by soil-applied chelating agents. Environ Sci Technol. 1997;31(3):860-5.

6. Liu Y, Tang H, Lin Z, Xu P. Mechanisms of acid tolerance in bacteria and prospects in biotechnology and bioremediation. Biotechnol Adv. 2015;33(7):1484-92.

7. Hassan ZU, Ali S, Rizwan M, Ibrahim M, Waseem M. Role of Bioremediation Agents (Bacteria, Fungi, and Algae) in Alleviating Heavy Metal Toxicity. In: Kumar V, Kumar M, Sharma S, Prasad R, editors. Probiotics in Agroecosystem. Singapore: Springer; 2017. https://doi.org/10.1007/ 978-981-10-4059-7-27.

8. Forrest M, Moore T. Eucalyptus gunnii: A possible source of bioenergy? Biomass Bioenergy. 2008;32(10):978-80.

9. Wei JC, Huang CB, Long YD, Huang CQ, Qin GZ, Cai ZH. The growth performance of Eucalyptus dunnii and Eucalyptus grandis $\times$ E. urophylla in high altitude areas of northwestern Guangxi. Environ Sci Technol. 2014;31(04):43-5 (In Chinese)

10. Zhang J, A-Peng DU. Application prospect of Eucalyptus in remedying the polluted soil by heavy metal. Environ Sci Technol. 2010;27(02):43-7 (In Chinese).

11. Kang MM, Chen HY, Chen CG, et al. Microbial diversity in root zone soils of Acacia confusa and Eucalyptus urophylla polluted by heavy metals. J East China Normal Univ (Natural Sci). 2009;2:50-60. (In Chinese).

12. Hlail SH. Heavy metals accumulation in trees grown in Urban and Rural areas. GEP. 2019;07(8):69-75.

13. Chen YL, Liu S, Dell B. Mycorrhizal status of Eucalyptus plantations in south China and implications for management. Mycorrhiza. 2007;17(6):527-35.

14. Campos DTS, Silva MCS, Luz JMR, Telesfora RJ, Kasuya MCM. Mycorrhizal colonizations in Eucalypt plantations. Rev Arvore. 2011;35(5):965-74.

15. Masuda H, Ishimaru Y, Bashir K, Mori S, Nishizawa NK, Nakanishi H, et al. Overexpression of the OsZIP4 zinc transporter confers disarrangement of zinc distribution in rice plants. J Exp Bot. 2007;58(11):2909-15.

16. Qi J, Zhang H, Li X, Lu J, Zhang G. Concentrations, spatial distribution, and risk assessment of soil heavy metals in a $\mathrm{Zn}-\mathrm{Pb}$ mine district in southern China. Environ Monit Assess. 2016;188(7):413.

17. Grotz N, Guerinot ML. Molecular aspects of $\mathrm{Cu}$, Fe and $\mathrm{Zn}$ homeostasis in plants. Biochim Biophys Acta. 2006;1763(7):595-608.

18. Palmgren MG, Clemens S, Williams LE, Krämer U, Borg S, Schjørring JK, et al. Zinc biofortification of cereals: problems and solutions. Trends Plant Sci. 2008;13(9):464-73.

19. Chen B, Shen H, Li X, Feng G, Christie. Effects of EDTA application and arbuscular mycorrhizal colonization on growth and zinc uptake by maize (Zea mays L.) in soil experimentally contaminated with zinc. Plant Soil. 2004;261(1-2):219-29.

20. Gaur A, Adholeya A. Arbuscular-mycorrhizal inoculation of five tropical fodder crops and inoculum production in marginal soil amended with organic matter. Biol Fertil Soils. 2002;35(3):214-8. 
21. Sugiura Y, Akiyama R, Tanaka S, Yano K, Saito K. Myristate can be used as a carbon and energy source for the asymbiotic growth of arbuscular mycorrhizal fungi. Proc Natl Acad Sci. 2020;117(41):25779-88.

22. Janouskova M, Krak K, Wagg C, Storchova H, Caklova P, Vosatka M. Effects of inoculum additions in the presence of a preestablished arbuscular mycorrhizal fungal community. Appl Environ Microbiol. 2013;79(20):6507-15.

23. Huang M, Zhu Y, Li Z, Huang B, Luo N, Liu C, et al. Compost as a soil amendment to remediate heavy metal-contaminated agricultural soil: mechanisms, efficacy, problems, and strategies. Water Air Soil Pollut. 2016;227(10):359. https://doi.org/10.1007/s11270-016-3068-8.

24. Chatterjee A, Khan SR, Vaseem H. Exploring the Role of Mycorrhizae as Soil Ecosystem Engineer. Mycorrhizosphere and Pedogenesis (eds Varma A and Choudhary D). 2019;4:73-93.

25. Leung HM, Ye ZH, Wong MH. Interactions of mycorrhizal fungi with Pteris vittata (As hyperaccumulator) in As-contaminated soils. Environ Pollut. 2006;139(1):1-8.

26. Arriagada CA, Herrera MA, Ocampo JA. Beneficial effect of saprobe and arbuscular mycorrhizal fungi on growth of Eucalyptus globulus co-cultured with Glycine max in soil contaminated with heavy metals. J Environ Manag. 2007:84(1):93-9.

27. Arriagada CA, Herrera MA, Ocampo JA. Contribution of arbuscular mycorrhizal and saprobe fungi to the tolerance of Eucalyptus globulus to Pb. Water Air Soil Pollut. 2005;166(1-4):31-47.

28. Bouain N, Shahzad Z, Rouached A, Khan GA, Rouached H. Phosphate and zinc transport and signalling in plants: Toward a better understanding of their homeostasis interaction. J Exp Bot. 2014;65(20):5725-41.

29. Smith JE, Read DJ. Mycorrhizal symbiosis. 3rd ed. London: Academic Press; 2008.

30. Watts-Williams SJ, Patti AF, Cavagnaro TR. Arbuscular mycorrhizas are beneficial under both deficient and toxic soil zinc conditions. Plant Soil. 2013;371(1-2):299-312

31. Blasco B, Graham NS, Broadley MR. Antioxidant response and carboxylate metabolism in Brassica rapa exposed to different external Zn, Ca, and Mg supply. J Plant Physiol. 2015;176:16-24.

32. Taylor KM, Nicholson RI. The LZT proteins; the LIV-1 subfamily of zinc transporters. Biochim Biophys Acta. 2003;1611(1-2):16-30.

33. Prem N, Basa S, Antala R, et al. A zinc (II) photocage based on a decarboxylation metal ion release mechanism for investigating homeostasis and biological signaling. Angew Chem. 2015;127(44):13219-23.

34. Pedas P, Ytting CK, Fuglsang AT, Jahn TP, Husted J. Manganese efficiency in barley: identification and characterization of the metal ion transporter HVIRT. Plant Physiol. 2008;148(1):455-66.

35. Barberon M, Dubeaux G, Kolb C, Isono E, Zelazny E, Vert G. Polarization of IRON-REGULATED TRANSPORTER 1 (IRT1) to the plant-soil interface plays crucial role in metal homeostasis. Proc Natl Acad Sci. 2014;111(22):8293-8.

36. Watts-Williams SJ, Tyerman SD, Cavagnaro TR. The dual benefit of arbuscular mycorrhizal fungi under soil zinc deficiency and toxicity: linking plant physiology and gene expression. Plant Soil. 2017;420:375-88.

37. Abreu I, Saéz Á, Castro-Rodríguez R, Escudero V, González-Guerrero M, Senovilla M, et al. Medicago truncatula Zinc-Iron Permease6 provides zinc to rhizobia-infected nodule cells. Plant Cell Environ. 2017;215(11):12

38. López-Millán AF, Ellis DR, Grusak MA. Identification and characterization of several new members of the ZIP Family of metal ion transporters in Medicago Truncatula. Plant Mol Biol. 2004;54(4):583-96.

39. Hocking PJ, Cambridge ML, Mccomb AJ. Nutrient accumulation in the fruits of two species of seagrass, Posidonia australis and Posidonia sinuosa. Ann Bot. 1980;45(2):149-61.

40. Milner MJ, Jesse S, Eric C, Kochian LV. Transport properties of members of the ZIP family in plants and their role in $\mathrm{Zn}$ and $\mathrm{Mn}$ homeostasis. J Exp Bot. 2013;1:369-81.

41. Grotz N, Fox T, Connolly E, Park W, Eide GD. Identification of a family of zinc transporter genes from Arabidopsis that respond to zinc deficiency. Proc Natl Acad Sci. 1998;95(12):7220-4

42. Ferrol N, Tamayo E, Vargas P. The heavy metal paradox in arbuscular mycorrhizas: from mechanisms to biotechnological applications. J Exp Bot. 2016;67(22):6253-65.

43. Han YC, Xie XA, Fan XN, Pu MY, Lin H, Zhao B. Cloning and expression regulation of a ZIP family of transporter gene AsZIP2 in arbuscular mycorrhizal roots of Astragalus sinicus. GAB. 2016;35(3):610-21 (In Chinese).

44. Burleigh SH, Kristensen BK, Bechmann IE. A plasma membrane zinc transporter from Medicago truncatula is up-regulated in roots by $\mathrm{Zn}$ fertilization, yet down-regulated by arbuscular mycorrhizal colonization. Plant Mol Biol. 2003;52(5):1077-88.

45. Xiao YP, Shao YF, Shen SY, Yin R, Chen YC. Effect of arbuscular mycorrhizal fungi and earthworms on phytoremediation of as-contaminated soils using maizet. J Ecol Rural Environ. 2011;26(3):235-40.

46. Sancenón V, Puig S, Mira H, Thiele DJ, Peñarrubia L. Identification of a copper transporter family in Arabidopsis thaliana. Plant Mol Biol. 2003:51(4):577-87.

47. Blaby-Haas CE, Merchant SS. The ins and outs of algal metal transport. Biochim Biophys Acta. 2012;1823(9):1531-52.

48. Sancenon V, Puig S, Mateu-Andres I, Dorcey E, Thiele DJ, Penarrubia L. The Arabidopsis copper transporter COPT1 functions in root elongation and pollen development. J Biol Chem. 2004;279(15):15348.

49. Zhang HZ, Yang JL, Wang WD, Li DD, Hu XQ, Wang H, et al. Genomewide identification and expression profiling of the copper transporter gene family in Populus trichocarpa. Plant Physiol Biochem. 2015;97:451-60.

50. Klaumann S, Nickolaus SD, Fürst SH, Starck S, Schneider S, Trentmann NO. The tonoplast copper transporter COPT5 acts as an exporter and is required for interorgan allocation of copper in Arabidopsis thaliana. New Phytol. 2011;192(2):393-404.

51. Martins V, Hanana M, Blumwald E, Gerós H. Copper transport and compartmentation in grape cells. Plant Cell Physiol. 2012;53(11):1866-80

52. Vatansever R, Ozyigit II, Filiz E. Genome-wide identification and comparative analysis of copper transporter genes in plants. Interdiscip Sci. 2017:9(2):278-91.

53. Aller $\mathrm{S}$, Unger V. Projection structure of the human copper transporter CTR1 at 6- resolution reveals a compact trimer with a novel channel-like architecture. Proc Natl Acad Sci. 2006;103(10):3627-32.

54. Burleigh $\mathrm{SH}$, Bechmann IE. Plant nutrient transporter regulation in arbuscular mycorrhizas. Plant Soil. 2002;244(1-2):247-51.

55. Curie C, Cassin G, Couch D, Divol F, Higuchi K, Le Jean M, et al. Metal movement within the plant: contribution of nicotianamine and yellow stripe 1-like transporters. Ann Bot. 2009;103(1):1-11.

56. Suzuki K, Higuchi K, Nakanishi H, Nishizawa NK, Mori S. Cloning of nicotianamine synthase genes from Arabidopsis thaliana. Soil Sci Plant Nutr. 1999:45(4):993-1002.

57. Curie C, Briat J. Iron transport and signaling in plants. Annu Rev Plant Biol. 2003;54(1):183-208.

58. Lubkowitz M. The oligopeptide transporters: a small gene family with a diverse group of substrates and functions. Mol Plant. 2011:4(003):407-15.

59. Conte SS, Walker EL. Transporters contributing to iron trafficking in plants. Mol Plant. 2011;4(3):464-76.

60. Gendre D, Czernic P, Conéjéro G, Pianelli K, Mari S. TCYSL3, a member of the YSL gene family from the hyperaccumulator Thlaspi caerulescens, encodes a nicotianamine-Ni/Fe transporter. The Plant J. 2007:49(1):1-15.

61. Cobbett HCS. A novel major facilitator superfamily protein at the tonoplast influences zinc tolerance and accumulation in Arabidopsis. Plant Physiol. 2007;143(4):1705-19.

62. Haydon MJ, Kawachi M, Wirtz M, Hillmer S, Hell R, Kramer U. Vacuolar nicotianamine has critical and distinct roles under iron deficiency and for zinc sequestration in Arabidopsis. Plant Cell. 2012;24(2):724-37

63. Ricachenevsky FK, Sperotto RA, Menguer PK, Sperb ER, Lopes KL, Fett JP. ZINC-INDUCED FACILITATOR-LIKE family in plants: lineagespecific expansion in monocotyledons and conserved genomic and expression features among rice (Oryza sativa) paralogs. BMC Plant Biol. 2011;11(1):20.

64. Li CY, Li CH. Bioinformatics analysis of ZIF1 homologous gene in Populus trichocarpa. J Anhui Agricultural University. 2013;40(3):492-500 (In Chinese).

65. Haydon MJ, Cobbett CS. Transporters of ligands for essential metal ions in plants. New Phytol. 2007;174(3):499-506. 
66. Chong K, Cobbett CS. HMA P-type ATPases are the major mechanism for root-to-shoot Cd translocation in Arabidopsis thaliana. New Phytol. 2010;181(1):71-8.

67. Axelse KB. Inventory of the superfamily of p-type ion pumps in Arabidopsis. Plant Physiol. 2001;126(2):696-706.

68. Takahashi R, Ishimaru Y, Shimo H, Ogo Y, Senoura T, Nishizawa NK, et al. The OsHMA2 transporter is involved in root-to-shoot translocation of $\mathrm{Zn}$ and Cd in rice. Plant Cell Environ. 2012;35(11):1948-57.

69. Eren E, Kennedy DC, Maroney MJ, Arguello JM. A novel regulatory metal binding domain is present in the $\mathrm{C}$ terminus of Arabidopsis $\mathrm{Zn}^{2+}$-ATPase HMA. J Biol Chem. 2006;281(45):33881-91.

70. Verret F, Gravot A, Auroy P, Leonhardt N, David P, Nussaume L, et al. Overexpression of AtHMA4 enhances root-to-shoot translocation of zinc and cadmium and plant metal tolerance. FEBS Lett. 2004;576(3):0-312.

71. Ouziad F, Hildebrandt U, Schmelzer E, Bothe H. Differential gene expressions in arbuscular mycorrhizal-colonized tomato grown under heavy metal stress. J Plant Physiol. 2005;162(6):0-649.

72. Sato Y, Antonio B, Namiki N, Motoyama R, Sugimoto K, Takehisa H, et al. Field transcriptome revealed critical developmental and physiological transitions involved in the expression of growth potential in japonica rice. BMC Plant Biol. 2011;11(1):10.

73. Kim YY, Choi H, Segami S, Cho HT, Lee Y. AtHMA1 contributes to the detoxification of excess Zn (II) in Arabidopsis. The Plant J. 2009;58(5):737-53.

74. Lee S, Kim YY, Lee Y, An G. Rice P1B-Type heavy-metal ATPase, OsHMA9, is a metal efflux protein. Plant Physiol. 2007;145(3):831-42.

75. Nies DH, Silver $\mathrm{S}$. Ion efflux systems involved in bacterial metal resistances. J Ind Microbiol. 1995;14(2):186-99.

76. Paulsen IT, Beness AM, Saier MH. Computer-based analyses of the protein constituents of transport systems catalysing export of complex carbohydrates in bacteria. Microbiology. 1997;143(Pt8):(8):2685

77. Kolaj-Robin O, Russell D, Hayes KA, Pembroke JT, Soulimane. Cation diffusion facilitator family: structure and function. FEBS Lett. 2015;589(12):1283-95

78. Sinclair SA, Kramer U. The zinc homeostasis network of land plants. Biochim Biophys Acta. 2012;1823(9):1553-67.

79. Göhre V, Paszkowski U. Contribution of the arbuscular mycorrhizal symbiosis to heavy metal phytoremediation. Planta. 2006;223(6):1115-22.

80. Delhaize E, Gruber BD, Pittman JK, White RG, Richardson AE. A role for the AtMTP11 gene of Arabidopsis in manganese transport and tolerance. Plant J. 2010;51(2):198-210.

81. Ma G, Li J, Li J, Li Y, Gu D, Chen C, et al. OsMTP11, a trans-Golgi network localized transporter, is involved in manganese tolerance in rice. Plant Sci. 2018;274:59-69.

82. Raghothama KG. Phosphate acquisition. Annu Rev Plant Physiol Plant Mol Biol. 1999;50(7):665-93

83. Schachtman DP, Reid RJ, Ayling SM. Phosphorus uptake by plants: from soil to cell. Plant Physiol. 1998;116(2):447-53.

84. Harrison MJ, Dewbre GR, Liu J. A phosphate transporter from Medicago truncatula involved in the acquisition of phosphate released by arbuscular mycorrhizal fungi. Plant Cell. 2002;14(10):2413-29.

85. Hata S, Kobae Y, Banba M. Interactions between plants and arbuscular mycorrhizal fungi. Elsevier Sci Technol. 2010;281:1-48.

86. Javot H, Penmetsa RV, Terzaghi N, Cook DR, Harrison MJ. A Medicago truncatula phosphate transporter indispensable for the arbuscular mycorrhizal symbiosis. Proc Natl Acad Sci. 2007;104(5):1720-5.

87. Chen A, Chen X, Wang H, Liao D, Gu M, Qu H, et al. Genome-wide investigation and expression analysis suggest diverse roles and genetic redundancy of Pht 1 family genes in response to Pi deficiency in tomato. BMC Plant Biol. 2014;14(1):1-15.

88. Mattsson M, Schjoerring JK. Dynamic and steady-state responses of inorganic nitrogen pools and $\mathrm{NH}$ (3) exchange in leaves of Lolium perenne and Bromus erectus to changes in root nitrogen supply. Plant Physiol. 2002;128(2):742-50.

89. Okamoto M, Kumar A, Li WB, Wang Y, Siddiqi MY, Crawford NM, et al. High-affinity nitrate transport in roots of Arabidopsis depends on expression of the NAR2-Like Gene AtNRT3.1. Plant Physiol. 2006;140(3):1036-46.

90. Hao DL, Yang SY, Liu SX, Zhou JY, Su YH. Functional characterization of the Arabidopsis ammonium transporter AtAMT1;3 with the emphasis on structural determinants of substrate binding and permeation properties. Front Plant Sci. 2020;11:571.

91. Hao HL, Wei $Y Z$, Yang XE, Feng Y, Wu CY. Effects of different nitrogen fertilizer levels on Fe, Mn, Cu and $\mathrm{Zn}$ concentrations in shoot and grain quality in Rice (Oryza sativa). Rice Sci. 2007;14(4):289-94.

92. Erenoglu EB, Kutman UB, Ceylan Y, Yildiz B, Cakmak I. Improved nitrogen nutrition enhances root uptake, root-to-shoot translocation and remobilization of Zn ( ${ }^{65} \mathrm{Zn}$ ) in wheat. New Phytol. 2011;189(2):438-48.

93. Khan IU, Ali A, Yun DJ. Arabidopsis NHX Transporters: sodium and potassium antiport mythology and sequestration during ionic stress. J Plant Biol. 2018;61(5):292-300.

94. Belova LP, Velikanov GA, II'Ina TM. The role of proton pump and potassium channels of plasma membrane in regulation of cellulose synthesis in plants. Tsitologiia. 2005:47(7):649-53.

95. Charoenpakdee S, Cherdchai P, Dell B, Lumyong S. The mycorrhizal status of indigenous arbuscular mycorrhizal fungi of physic nut (Jatropha curcas) in Thailand. Mycosphere. 2010;1(2):167-81.

96. Hoagland DR, Arnon DI. The water culture method for growing plants without soil. Calif Agric Exp Stn Circ. 1950;347:1-32.

97. Jiang Y, Wang WX, Xie QJ, Liu N, Liu LX, Wang DP, et al. Plants transfer lipids to sustain colonization by mutualistic mycorrhizal and parasitic fungi. Science. 2017;356(6343):1172-5.

98. Grabherr M, Haas B, Yassour M, Levin J, Thompson D, Amit I, et al. Rapid nitric acid digestion of plant material with an open-vessel microwave system. Commun Soil Sci Plant Anal. 2004;35(3-4):427-40.

99. Grabherr MG, Haas BJ, Yassour M, Levin JZ, Thompson DA, Amit I, et al. Full-length transcriptome assembly from RNA-Seq data without a reference genome. Nat Biotechnol. 2011;29(7):644-52.

100. Conesa A, Gotz S, Garcia-Gomez JM, Terol J, Talon M, Robles M. Blast2GO: a universal tool for annotation, visualization and analysis in functional genomics research. Bioinformatics. 2005;21(18):3674-6.

101. Powell S, Szklarczyk D, Trachana K, Roth A, Bork P. Orthologous groups covering 1133 organisms at 41 different taxonomic ranges. Nucleic Acids Res. 2011;40(Database issue):D284-9.

102. Mortazavi A, Williams BA, Mccue K, Schaeffer L, Wold B. Mapping and quantifying mammalian transcriptomes by RNA-Seq. Nat Methods. 2008;5:621-8.

103. Darby AC, Armstrong SD, Bah GS, Kaur G, Hughes MA, Kay SM, et al. Analysis of gene expression from the Wolbachia genome of a filarial nematode supports both metabolic and defensive roles within the symbiosis. Genome Res. 2012;22:2467-77.

104. Anders S, Huber W. Differential expression analysis for sequence count data. Genome Biol. 2010;11(10):R106.

105. Benjamini Y, Hochberg Y. Controlling the False Discovery Rate: A practical and powerful approach to multiple testing. J Royal Stat Soc Series B Methodol. 1995;57(1):289-300.

\section{Publisher's Note}

Springer Nature remains neutral with regard to jurisdictional claims in published maps and institutional affiliations.

Ready to submit your research? Choose BMC and benefit from:

- fast, convenient online submission

- thorough peer review by experienced researchers in your field

- rapid publication on acceptance

- support for research data, including large and complex data types

- gold Open Access which fosters wider collaboration and increased citations

- maximum visibility for your research: over $100 \mathrm{M}$ website views per year

At BMC, research is always in progress.

Learn more biomedcentral.com/submissions 